\title{
Replumbing the Bengal Basin: A Shift in Recharge Driven by Groundwater Irrigation Revealed by Stable Water Isotopes
}

Yusuf Jameel ( $\nabla$ yjameel@mit.edu )

Massachusetts Institute of Technology https://orcid.org/0000-0001-8564-4611

Mason Stahl

Union College

Holly Michael

University of Delaware

Benjamin Bostick

Columbia University

Mike Steckler

Columbia University

Peter Schlosser

Arizona State University

Alexander van Geen

Columbia University

Charles Harvey

Massachusetts Institute of Technology

Article

Keywords: Stagnant Surface Water Bodies, Direct Infiltration of Rain, Irrigated Rice, Aquifers

Posted Date: May 7th, 2021

DOI: https://doi.org/10.21203/rs.3.rs-457036/v1

License: (1) (1) This work is licensed under a Creative Commons Attribution 4.0 International License.

Read Full License 


\section{$1 \quad$ Replumbing the Bengal Basin: A Shift in Recharge Driven by 2 Groundwater Irrigation Revealed by Stable Water Isotopes}

Yusuf Jameel ${ }^{1 *}$, Mason Stahl ${ }^{2}$, Holly Michael $^{3}$, Ben Bostick ${ }^{4}$, Michael S Steckler $^{4}$, Peter Schlosser ${ }^{5}$, Alexander van Geen ${ }^{4}$ and Charles Harvey ${ }^{1}$

${ }^{1}$ Department of Civil and Environmental Engineering, Massachusetts Institute of Technology, 15

8 Vassar Street, Cambridge, MA 02139.

92 Department of Geology, Union College, 807 Union Street, Schenectady, NY 12308.

$10{ }^{3}$ Department of Civil and Environmental Engineering, University of Delaware, 255 Academy

11 Street, Newark, DE 19716.

$12{ }^{4}$ Lamont-Doherty Earth Observatory, Columbia University, Palisades, New York 10964.

135 Julie Ann Wrigley Global Futures Laboratory, Arizona State University, Tempe, AZ.

* corresponding author, Email: yjameel@mit.edu 


\section{Abstract}

Groundwater supports agriculture and provides domestic water for over 250 million 19 people in the Bengal Basin. Our analysis of stable water isotope ratios in rain, surface, and 20 groundwater shows that the proportion of groundwater recharge originating from stagnant surface 21 water bodies has increased by about $50 \%$ over the last seventy years while the relative contribution 22 from direct infiltration of rain has decreased. This regional shift in the source of groundwater 23 shows how the simultaneous expansion of irrigated rice, excavated ponds and groundwater 24 pumping has changed the hydrologic system by cycling evaporated standing water through the 25 subsurface. Analysis of water isotope data also reveals that most recharge from standing water 26 enters during the latter part of the dry season (February-April), while most rainwater recharge 27 occurs in the early months of the monsoon (June-August) before aquifers fill to capacity and reject 28 additional recharge of rainwater. 


\section{Introduction}

Groundwater is the main source of domestic and agricultural water for more than 250 million people living in the Bengal Basin of Bangladesh and India that lies in the downstream floodplains and deltas of the Ganges, Brahmaputra and Meghna Rivers (1-3). Large-scale abstraction of groundwater over the last six decades for dry-season agriculture has increased recharge to groundwater (4-7), caused the water table to decline further during the dry season and, in some parts of the basin, prevented the water table from rebounding as high during the monsoon $(1,6)$. Pumping draws more shallow water to deeper aquifers increasing the risk of contaminating relatively low-arsenic deep groundwater aquifers $(8,9)$ and making coastal aquifers more vulnerable to seawater intrusion (10). Understanding the ramifications of large-scale pumping on groundwater dynamics is important for future sustainability of both the quantity and quality of groundwater, the main source for household and irrigation water in the basin (11).

Groundwater in the Bengal Basin has been assumed to be recharged by direct monsoon precipitation $(9,12-15)$ largely based on the fact that rainfall exceeds potential evapotranspiration. Several site-specific studies have challenged this notion by finding that shallow groundwater aquifers today are recharged by rivers, local ponds and rice field water (16-20). Irrigation pumping induces downward head gradients beneath these surface sources that increase as the water table falls towards its dry-season minimum. Because recharge occurs while the water table is falling annual recharge cannot be estimated by analysis of the rising portion of the groundwater hydrograph alone. Groundwater hydrographs alone do not provide enough information to estimate recharge.

The contribution of the different sources in the geomorphically active Bengal Basin can vary spatially and temporally. Older groundwater may contain recharge from surface water bodies that no longer exist because river meandering and avulsion moves channels across the landscape over decades and centuries (21). For instance, the Brahmaputra flowed on the eastern side of the Dhaka until it avulsed about 200 years ago and now flows about $80 \mathrm{~km}$ west of Dhaka $(22,23)$. Hydrograph analyses show that groundwater recharge has increased in the last three decades due to intensive groundwater abstraction for irrigation. These studies argue that the increased recharge is sourced from direct rain infiltration and river water $(6,24)$ during the monsoon. However, prior regional scale studies have not (1) quantified the contributions of different recharge sources, (2) accounted for recharge from ponds and rice fields (3) analyzed how recharge sources have changed over decades and centuries.

Regional water and land use changes suggest that ponds and rice fields could contribute significantly to groundwater recharge primarily during the dry season. In the last 35 years, the number of irrigation wells has increased from $<100,000$ to $>1.7$ million (25) primarily to support dry-season irrigation that has also correspondingly increased from $<1$ million hectares to 5 million hectares $(\sim 20 \%$ of the total land) $(26,27)$. Groundwater abstraction in Bangladesh is estimated to be $>33 \mathrm{~km}^{3}$ in $2010,95 \%$ of which is used to support dry season farming (28); a volume that can fill the 5 million hectares with a water depth equaling $650 \mathrm{~mm}$. The volume of groundwater abstraction in Bangladesh and West Bengal (India) has only increased in recent times (25). At least 10 million hand-pumped wells have also been installed in the region, but they account for only a minor fraction of total pumping (29). Man-made ponds cover an estimated $2.6 \%$ of the area of Bangladesh, with more than 4 million households owning a pond (30); most of these ponds are recent and have been constructed in the past 70 years (31), although the number of ponds may be stabilizing post-2000 (32). 

declines in the water table elevation and the growth of standing water in rice fields and ponds, motivated us to investigate how groundwater recharge may have changed over time. We postulate that: 1) rice fields, pond water and rivers have now become a major contributor to groundwater recharge across the basin and 2) the majority of the recharge from standing water occurs during the latter part of the dry season (February to April) when groundwater levels reach their minima so that large vertical head gradients draw more recharge from standing water into the available aquifer storage.

In this work, we rely on radiogenic and stable water isotopes to answer our hypotheses. We first establish the regional groundwater age profile by compiling existing radiocarbon and tritium groundwater data from the region. Subsequently we partition the contribution of different sources recharging shallow groundwater in the Bengal Basin using stable water isotopes that are used extensively for partitioning the contributions of different water sources in urban, natural and ecohydrological water systems (33-36). We compiled the existing groundwater stable water isotope ratios $\left(\delta^{2} \mathrm{H}\right.$ and $\left.\delta^{18} \mathrm{O}\right)$ for Bangladesh and the eastern portion of West Bengal (bordering Bangladesh) and model the groundwater stable isotope ratios as a mixture of precipitation, standing water (local rivers, ponds and rice fields), and large rivers (Ganges and Brahmaputra) to estimate the contribution of each source to groundwater. The contrast between isotopically enriched standing water (due to evaporation) in comparison to isotopically light large Himalayan rivers (Ganges and Brahmaputra and their tributaries) and unevaporated precipitation values provide the necessary isotopic separation to quantify the contribution of these sources to groundwater recharge. Finally, we interpret the modeling results alongside long-term groundwater hydrographs from the region to develop a simplified regional recharge model.

\section{Data source and conceptual framework}

\section{Groundwater age profile of the Bengal Basin}

Radioactive isotopes in groundwater indicate that in the upper 100 meters of the aquifer system much of the groundwater was recharged contemporaneously with the onset of groundwater irrigated rice and the expansion of man-made ponds (37). Tritium active water is pervasive up to a depth of $100 \mathrm{~m}$ (Figure 1A) indicating modern recharge (post-1953) and highlighting vigorous groundwater circulation. Approximately $60 \%$ and $20 \%$ of the groundwater samples in shallow $(0-$ $50 \mathrm{~m}$ depth) and intermediate (50-100 m depth) wells have a tritium activity of $>1 \mathrm{TU}$. However, groundwater with tritium levels below detection limits are also present throughout the vertical profile, indicating that older stagnant water can be found at all depths. Below $100 \mathrm{~m}$, tritium concentrations decline, but tritium-active water is still found where data is available to a depth of $300 \mathrm{~m}$ indicating young water, less than 70 years old, although some of these wells may be compromised by leaks in their casing $(38,39)$. Radiocarbon dating suggests that waters from below $100 \mathrm{~m}$ are, on average, thousands of years old. A linear regression of uncorrected dissolved inorganic radiocarbon age on depth suggests that water at $100 \mathrm{~m}$ depth is on average 4000 years old and 10,000 years old below $200 \mathrm{~m}$, reflecting recharge that predates human influence and occurred most likely during early Holocene and late Pleistocene (Figure1B). 


\section{Stable water isotope data}

We combined stable water isotope data for precipitation, groundwater and surface water (rivers, ponds and puddled water in rice fields) for the Bengal Basin from 31 sources (Table S1) that together provide 580 precipitation, 1918 groundwater and 487 surface water values. Precipitation samples were collected at Barasat and Kolkata in India and at Savar, Barisal, Sylhet, Chittagong and Cox's Bazar in Bangladesh (15, 40-43). The distribution of precipitation stations provided an extensive spatial coverage of precipitation isotope ratios from the basin (Figure 2A). Groundwater samples were evenly distributed across Bangladesh and the bordering region between Bangladesh and West Bengal lying to the East of the Hooghly River (tributary of the Ganges, Figure 2). Some locations had high densities of groundwater isotope data as they have been studied extensively for groundwater arsenic $(17,19,44-46)$. The lack of isotopic data from the districts west of the Hooghly River in West Bengal is largely due to the fact that they have been investigated to a lesser extent for groundwater arsenic contamination.

For all of the investigated precipitation sampling stations across the Bengal Basin (Figure 2) isotope values varied seasonally with the heaviest values during the dry season (January-April), followed by decline isotope ratios at the onset of monsoon and the lightest values during late monsoon (September/October, Figure $3 \mathrm{~A}$ and 3B). This seasonal pattern in the precipitation isotope ratios is consistent across the Bengal Basin (43, 47). Rainfall is highly seasonal, and the majority of precipitation occurs during the monsoon months of May to October (Figure 3C). The stable isotope ratios of precipitation showed a wide range of values from -120 to $25 \%$ o $\left(\delta^{2} \mathrm{H}\right)$ and 15 to $5 \%$ ( $\left(\delta^{18} \mathrm{O}\right)$. The amount-weighted mean $\delta^{2} \mathrm{H}$ and $\delta^{18} \mathrm{O}$ of annual precipitation is $-46.5 \%$ and $-6.9 \%$ respectively. We define the local meteoric water line $\left(\mathrm{LMWL}, \delta^{2} \mathrm{H}=8.2 \delta^{18} \mathrm{O}+11.2, \mathrm{R}^{2}=\right.$ $0.97, \mathrm{p}<0.05)$ as the best-fit regression line through all the precipitation data.

We divided surface water samples in groups representing (a) large rivers (Ganges and Brahmaputra) and (b) standing water (small rivers, ponds and rice fields). The Bengal Basin is a deltaic system with an intricate network of streams and rivers. In this analysis, by large rivers we refer to the main Ganges and Brahmaputra channel as well as the tributaries feeding from the main channels - a large proportion of water in these rivers is derived from Himalayan snowmelt and higher altitude precipitation (48). This water is isotopically lighter (49) than the amount weighted mean precipitation isotope ratios of the Bengal Basin (Figure 4A). We define standing water as waterbodies that are recharged primarily from the local precipitation in the Bengal Basin and subsequently undergo evaporative enrichment during the dry season. This includes: 1) Ponds that are filled up during the monsoon and are depleted by human consumption and evaporation during the dry season, 2) Small rivers that do not contain water from the large rivers and may become stagnant during the dry season, 3) Standing water in irrigated rice fields.

Samples from large rivers (Ganges and Brahmaputra) were isotopically lighter than the standing water samples (Figure 4A), falling around the LMWL and clustering around the point $50 \%$ o $\left(\delta^{2} \mathrm{H}\right)$ and $-7.4 \%$ o $\left(\delta^{18} \mathrm{O}\right)$. Seasonal data from the Ganges were typically lighter and show a subdued isotopic variation compared to local precipitation suggesting significant contribution from isotopically depleted Himalayan tributaries (48). Multi-year $\delta^{18} \mathrm{O}$ isotope values from the Brahmaputra fell between -12 and $-6 \%$ o (mean $=-8 \%$ ) with heavier values observed during April and depleted values observed during late monsoon due to large contributions from snow and glacier melt and high-elevation precipitation (49). The slope of the river water line is $>7(15,48$, $49)$ suggesting negligible evaporative enrichment of stable water isotopes in these rivers.

In contrast to large rivers, standing water samples showed a large range of isotope values (Figure 4A). Seasonal measurements suggests that standing water undergoes progressive 
evaporative enrichment during the dry season (November to April) and the heaviest isotope values were observed towards the end of the dry season in March/April $(13,19)$. The evaporation slope obtained by regressing through the standing water data was $5.6\left(\delta^{2} \mathrm{H}=5.6 \delta^{18} \mathrm{O}-7.6, \mathrm{R}^{2}=0.90, \mathrm{p}\right.$ $<0.05$, Fig $4 \mathrm{~A}$ ), very similar to the theoretically calculated evaporation slope (between 5 and 6 ) in the Bengal Basin (50) indicating evaporative enrichment of standing water bodies.

The stable isotope ratios of groundwater showed a wide range of values from - 64.0 to $5.3 \%$

\section{Groundwater isotope mixing models}

Groundwater in the Bengal Basin can be recharged by multiple sources including direct rainfall, large rivers (Ganges, Brahmaputra and their tributaries), bodies of standing water (irrigated rice fields and ponds), small rivers, or a combination of these sources. The contribution from the different sources can vary locally depending upon the precipitation, proximity of the aquifer to rivers, the hydrological connectivity between the rivers and the aquifers, and the density of standing water bodies (ponds and rice fields) above the aquifer. Furthermore, these sources and their relative contributions have likely varied over time due to changes in climate, land use, and water use.

These sources can be divided into three isotopic endmembers. First, the isotopically light water in Ganges and Brahmaputra and their tributaries (Figure 4A). Second, precipitation isotope ratios $\left(\delta^{2} \mathrm{H}\right.$ and $\left.\delta^{18} \mathrm{O}\right)$ that exhibit a large range, however, are strongly correlated and fall on or close to the LMWL (Figure 3A). Third, ponds, local rivers and rice fields isotope ratios that show strong seasonal variation. Samples collected from ponds and local rivers during the monsoon season lie close to the LMWL and undergo evaporative enrichment during the non-monsoon season (November to April) which makes then isotopically heavier than local precipitation (Figure 4A). Similarly, standing water in rice fields (pumped from the groundwater) undergo evaporative enrichments during the dry season and gets evaporatively enriched over time. Thus, there is a clear distinction between non-evaporated water sources (large rivers and precipitation) and evaporated standing water sources (local rivers, ponds and rive fields, Figures 4 and S3). With this variation in the isotopic signature $\left(\delta^{2} \mathrm{H}\right.$ and $\left.\delta^{18} \mathrm{O}\right)$ of the endmembers, we model the proportion of groundwater isotope ratios as a mixture of precipitation, standing water and large rivers.

Several combinations of precipitation, river and standing water isotope values can explain the observed isotope ratios of groundwater samples (Figure S3B and 5). Therefore, we use a Monte-Carlo approach to find non-parametric distributions that describe possible mixes of recharge reflected by groundwater isotope values. We constructed three different mixing models, each with uniquely different assumptions about the source of recharge, to test the sensitivity of the results to these assumptions. Complete details are provided in Methods section.

In the first model, groundwater isotope ratios are modeled as a linear mixture of a precipitation and standing water sample (Figure 5A), without any input from large rivers (Ganges 
and Brahmaputra). This assumes that groundwater is recharged primarily from precipitation and local surface waterbodies. The logic behind this assumption is that for regions not lying in the river floodplain it is unlikely that rivers contribute significantly to shallow groundwater recharge. Additionally, for sites in proximity to the Ganges and Brahmaputra, groundwater flow is toward the river, except during the latter part of the dry season when flow may be reversed as the groundwater head falls below the river water level due to extensive pumping $(51,52)$. During the early monsoon, some local recharge along the Brahmaputra may take place driven by a rising river stage from snowmelt in the headwaters. Water level in Ganges rises later in July (6), hence it does not contribute to early monsoon recharge.

In the second model, we considered a 3-endmember mixing model with large rivers, precipitation, and standing water as the potential sources (Figure 5B) - any combination of these sources could recharge the groundwater. The third model is also a 3 -endmember model with a standing water endmember and two precipitation endmembers (Figure 5C), but no river water. The idea behind the third model is to account for the possibility that groundwater samples contain a mix of two, rather than just one, precipitation sources with distinct isotopic compositions. Because precipitation isotope ratios vary systematically during the monsoon and transition from heavier to lighter $\delta^{18} \mathrm{O}$ and $\delta^{2} \mathrm{H}$ values from early to late monsoon, this model can quantify the relative contributions of each, and in doing so, the timing of recharge by precipitation. This model is similar to model 1 in regard to the source endmembers used in the model but generates an independent measure of contributions from standing water.

\section{Results}

We observed a large scatter in the $\delta^{18} \mathrm{O}$ and d-excess profile in shallow wells with values ranging from -7 to $0 \%$ o $\left(\delta^{18} \mathrm{O}\right)$ and -2 to $12 \%$ (d-excess, Figure $6 \mathrm{C}$ ). For the intermediate wells, the range of $\delta^{18} \mathrm{O}$ and d-excess starts to taper with depth and the range of $\delta^{18} \mathrm{O}$ and d-excess values at $100 \mathrm{~m}$ is much smaller than the range at $50 \mathrm{~m}$. Indeed below $75 \mathrm{~m}, \delta^{18} \mathrm{O}$ ranged from -6 to $-3 \%$ o and barring a handful of samples d-excess was mostly $>6 \%$. The large range of $\delta^{18} \mathrm{O}$ and d-excess in the shallow wells suggests that groundwater is recharged by a diverse suite of sources and during different time of the season. In contrast, the lower spread in $\delta^{18} \mathrm{O}$ and d-excess for intermediate and deeper wells suggests recharge is dominated by a single source.

The moving depth-average groundwater $\delta^{18} \mathrm{O}$ decreased from $-3.8 \%$ to $-5.1 \%$ o between 7 $\mathrm{m}$ and $100 \mathrm{~m}$ deep (Figure 6A). In the same depth interval, deuterium-excess increased from $4.6 \%$ to $7.2 \%$. Between $100 \mathrm{~m}$ and $250 \mathrm{~m}$, the moving depth-average groundwater $\delta^{18} \mathrm{O}$ increased from $-5.1 \%$ to $-3.8 \%$. The corresponding d-excess values did not change appreciably, increasing slightly from $7.2 \%$ o to $7.9 \%$ (Figure $6 \mathrm{C}$ ).

All three models, despite with their different assumptions, result in similar estimates of standing-water contribution. Model 2, which includes river input, shifts some of the estimated rainwater contribution to the river as both are unevaporated sources (i.e., lying on the LMWL) but still yields about the same contributions of the evaporated standing water source over depth. Precipitation is the largest contributor to groundwater recharge in all the mixing models. The fractional contributions of precipitation are $0.70 \pm 0.25,0.50 \pm 0.26$, and $0.74 \pm 0.22$ (mean $\pm \sigma$ ) in model 1 (precipitation and standing water), 2 (precipitation, river and standing water) and 3 (two precipitation and standing water), respectively. The mean contribution of standing water is $0.30 \pm 0.25,0.28 \pm 0.22$ and $0.26 \pm 0.24$ in models 1,2 and 3 , respectively. The mean contribution of rivers is $0.22 \pm 0.18$ in model 2 . 
The moving depth-average suggests that the mean contribution of the different sources varies with depth (Figure 7). The contribution of non-evaporated sources (precipitation in model 1 , precipitation and river in model 2, and the two precipitation sources in model 3) increases moving down from 7 meters to 100 meters depth, with proportions increasing from 0.60 to 0.74 (model 1), 0.63 to 0.77 (model 2), and 0.62 to 0.75 (model 3). The contribution from standing water at a depth of $7 \mathrm{~m}$ was more than 1.5 times the contribution at $100 \mathrm{~m}$, with values at 7 and $100 \mathrm{~m}$ respectively of 0.43 and 0.26 (model 1 ), 0.37 and 0.23 (model 2), and 0.38 and 0.25 (model 3). Between depths of 100 and $250 \mathrm{~m}$, the contribution of evaporated and non-evaporated sources exhibited more subdued changes with depth (Figure 7). Contributions of non-evaporated sources increased slightly between depths of 100 to $250 \mathrm{~m}$, with values at 100 and $250 \mathrm{~m}$ respectively of 0.74 and 0.81 (model 1), 0.77 and 0.82 (model 2), and 0.75 and 0.80 (model 3). Correspondingly, the contributions of standing water decreased between depths of $100 \mathrm{~m}$ and $250 \mathrm{~m}$, changing from 0.26 to 0.19 (model 1), 0.23 to 0.18 (model 2), and 0.25 to 0.20 (model 3). We did not observe any spatial pattern in the contribution of the different sources (see section "Spatial pattern in fractional contribution of the different sources" in the SM for details).

\section{Discussion}

\section{Temporal changes in groundwater isotope ratios}

The distinct trend in the depth-average groundwater isotope ratios $\left(\delta^{18} \mathrm{O}\right.$ and $\delta^{2} \mathrm{H}$, Figure 6) where it decreases from $7 \mathrm{~m}$ depth to $100 \mathrm{~m}$ depth and subsequently increases from $100 \mathrm{~m}$ depth to $267 \mathrm{~m}$ depth suggests that either the relative contribution of the isotopically distinct sources recharging groundwater has changed over time or the isotope ratios of the sources recharging groundwater have changed. In the Bengal Basin, it appears that both factors have contributed to variations in groundwater isotope ratios over time.

Enriched $\delta^{18} \mathrm{O}$ and $\delta^{2} \mathrm{H}$ values in shallow aquifers were associated with lower d-excess and vice-versa $(\mathrm{r}=-0.6)$; the inverse relation between the stable isotopes $\left(\delta^{18} \mathrm{O}\right.$ and $\left.\delta^{2} \mathrm{H}\right)$ and d-excess provides evidence that the pattern in moving depth-average groundwater isotope ratios between 7 to $100 \mathrm{~m}$ depth is primarily due to increase in contribution of unevaporated sources as we move to deeper depths. In other words, more recently recharged water (i.e., shallower depths) have higher contribution from evaporated sources (ponds, rice fields and local rivers during the dry season) and deeper water have lower contribution from evaporated sources. It is very unlikely that these patterns in the top 100 meters of groundwater represent changes in precipitation isotope ratios because most of this water recharged in the last millennium, much more recently than the last changes in rainfall isotope ratios that occurred about 10,000 years ago $(45,53)$.

Between $100 \mathrm{~m}$ and 267 meters depth, $\delta^{18} \mathrm{O}$ and $\delta^{2} \mathrm{H}$ reversed the trend observed between 7 and $100 \mathrm{~m}$ depth and become progressively enriched. However, the trend in d-excess did not reverse; instead, it increased nominally by $0.8 \%$ (Figure 6 ) suggesting that the changes in groundwater recharge are not driven by increase in contribution of evaporated water. Groundwater below $100 \mathrm{~m}$ is, on average older than 4000 years and below $200 \mathrm{~m}$ is, on average, older than 10,000 years (Figure 1B). In the Bengal basin, precipitation isotopes in the Pleistocene were isotopically heavier than in Holocene precipitation (53). Thus, the observed pattern in the depthaverage groundwater isotope ratios is most likely due to changes in the precipitation endmember values; the groundwater isotope ratios become progressively heavier with increasing depth as the component of older Pleistocene precipitation water increases. 


\section{Changes in groundwater recharge sources over time}

There is a broad consensus that large-scale pumping of groundwater has altered groundwater dynamics in the Bengal Basin by lowering the water table below large cities and intensively irrigated areas, drawing modern water into deeper aquifers and reversing streamgroundwater exchange during the dry-season $(3-5,8,18,51,54)$. Although field studies have suggested changes in recharge sources in response to groundwater pumping - mostly increased contribution from rice fields and ponds $(16-19,55)$ - a basin-wide shift in the sources recharging groundwater has not been reported. Previous and recent basin scale work has mostly focused on diffused and focused recharge during monsoon $(6,24)$ and have failed to explicitly consider the possible recharge from ponds and rice fields at regional level.

The trends in isotopic composition are mirrored by changes in source attribution between shallow, recent groundwater and older, deeper groundwater and provide clear evidence that recent human perturbations have affected groundwater recharge sources on a massive scale. In all the models, we observed a sharp transition in the contribution of standing water at the depth of $75 \mathrm{~m}$ (Figure 7). The standing water contribution decreases as we move downwards from $7 \mathrm{~m}$ to $75 \mathrm{~m}$. However, between 75-100 m depth, the fractional contribution of the different sources does not change appreciably. These differences in contribution with depth suggest that the proportion of recharge from the different sources recharging the groundwater has changed over time.

We interpret our results within the framework of the available groundwater dating (C14 and tritium concentration) to suggest that the relative contributions in recent times have shifted to contain more standing water sources that have been subjected to evaporation. Between 7 and 100 $\mathrm{m}$ depth, where the contribution of evaporated water is greatest, groundwater is dominantly modern, with more than $80 \%$ samples containing high tritium levels. The average tritium concentration decreases with depth providing evidence that the more recent the recharge is (i.e., shallower depths), the higher is the contribution of evaporated water. Recent work have suggested that total recharge has increased in the Bengal Basin in response to widespread pumping, however these studies could not partition the contribution from the different sources (24). Groundwater isotopic data and our mixing model suggests that the increased groundwater abstraction have not only increased the amount of recharge but have also drastically altered the sources recharging shallow groundwater aquifer in the Bengal Basin; evaporated water recharge during the dry season (discussed subsequently) have become a major recharge source of shallow groundwater.

Below $100 \mathrm{~m}$ depth, changes in $\delta^{18} \mathrm{O}$ and $\delta^{2} \mathrm{H}$ is not mirrored by corresponding changes in the contribution from the respective sources. Water below $100 \mathrm{~m}$ is typically $>4000$ years old suggesting recharge that predates human influence. Therefore, the proportional contribution of evaporated and non-evaporated sources has remained consistent even though the source water isotope ratios changed over time. Overall, it appears that in the last 70 years the contribution of mean contribution of standing water has steadily been increasing with time. For water recharged before large-scale human perturbation, during late Holocene to Pleistocene, the respective contribution of the sources has not changed appreciably.

This shift to increased fractions of standing water about 70 years ago coincides with the shift to groundwater-irrigated dry-season rice farming and the growth of pond excavation (31), both of which reflects the broader economic and population changes in the region. To our knowledge this is the first study to show that large-scale groundwater pumping has altered the source contributions to groundwater recharge in the Bengal Basin, with standing water in rice fields, ponds and local rivers are now acting as major recharge sources. 
The large decline $(\sim 1.6 \mathrm{~m})$ in the annual minimum water table depth across much of Bengal Basin (6) caused by groundwater extraction likely result in large vertical hydraulic gradient that draws recharge in from the surface water bodies. Dry-season irrigation in Bangladesh increased from $<1$ million hectares to 5 million hectares between 1975 and 2010 (26). Irrigated rice fields now cover $21 \%$ of the land area and standing water in these field recharges groundwater as irrigation return flow - groundwater pumped for irrigation that returns back to aquifers. Neumann et al. (27) showed that return flow recharges aquifers by passing through macropores beneath bunds (the raised berms that bound rice fields). This recharge circumvents the low-permeability plough pan, the near-surface layer that restricts flow directly through rice fields. They estimated the water budget for rice fields using an average ratio of field perimeter (bund length) to field area and found that rice fields recharge in excess of $100 \mathrm{~cm}$ of water per year. Other field level analysis also suggests significant water loss from rice fields from seepage and percolation. Working in the Barind tract (northwest Bangladesh) Qureshi et al. (58) reported that during the dry season only $55 \%$ of the total applied water to rice fields was lost to evapotranspiration and the remaining $45 \%$ was lost to seepage and percolation (56). On a seasonal basis, the authors estimated that net amount of seepage and percolation were 34 and $60 \mathrm{~cm}$ for the dry and monsoon season respectively (56).

Similarly man-made ponds $(31,57)$ can recharge shallow groundwater. Stahl et al., (19) have shown that the presence of terrestrial crab burrows in pond-beds can short-circuit lowpermeability surface sediments and provide widespread conduits for groundwater recharge; they estimated the recharge flux to be $223 \mathrm{~cm} /$ year at their field site.

Although on an annual time scale there is a net discharge from aquifers to the rivers (58), local rivers can also recharge shallow aquifers in response to lowering of groundwater level (24, 51 ) especially in the dry season when groundwater heads fall below the river head leading to flow reversal that can recharge the aquifer or during the early monsoon when river and stream stage rise precedes the rise in groundwater levels. Recharge from riverbeds is more complex than recharge from ponds and rice fields. There are two modes of recharge from small rivers: (1) recharge during the dry season when groundwater levels fall; (2) recharge in the early monsoon when river levels rise faster than groundwater levels. During the dry season small river behave like other standing water sources and have an isotopic signature indicating evaporation. This type of recharge is clearly identified as standing water from its isotope values. During the monsoon, however, small rivers act as conduits for recharge of precipitation and thus the isotopic signature matches that of early monsoon precipitation. This type of recharge, although passing through riverbeds, is identified as coming from precipitation in our model.

\section{Timing of recharge from precipitation and standing water}

Groundwater isotope ratios in temperate regions are isotopically similar to the precipitation amount-weighted isotope ratios (59-61). In the tropics, groundwater isotope ratios have been shown to be isotopically lighter than the amount-weighted precipitation isotope ratios, which has been interpreted as a recharge bias toward large rainfall events (62). However, unlike the commonly observed pattern in the tropics (62), a majority of shallow and intermediate groundwater isotope ratios (Figure 3) in the Bengal Basin are heavier than the modern amountweighted mean precipitation isotope ratios (-46.5\% and $-6.9 \%$ for $\delta^{2} \mathrm{H}$ and $\delta^{18} \mathrm{O}$ respectively).

Our mixing models suggests that the combination of precipitation to recharge is skewed towards heavier values along the meteoric mixing line (Figure 8). For all of the models, $70 \%$ of the precipitation isotope ratios estimated to contribute to recharge were heavier than $-6.9 \%$ (for $\delta^{18} \mathrm{O}$ ) - the amount weighted mean precipitation $\delta^{18} \mathrm{O}$ value. Therefore, our modeling suggest that 
groundwater is not recharged evenly across the monsoon season and is seasonally biased toward early monsoon rainfall, which is typically heavier than late monsoon precipitation (Figures $3 \mathrm{~A}$ and 3B).

For all the models, the contribution from isotopically-light standing water sources $\left(\delta^{18} \mathrm{O}<\right.$ $6 \%$ ) is low $(<10 \%)$ and the proportion of isotopically enriched $\left(\delta^{18} \mathrm{O}>-2 \%\right.$ ) standing water values is $>50 \%$ (Figures $8 \mathrm{~B} 1-\mathrm{B} 3$ ) suggesting that standing water recharges groundwater mostly during the latter part of the dry season when the standing water bodies have become isotopically enriched due to evaporation. Groundwater levels are lowest during the latter part of the dry season, which leads to an increase in the difference between surface water and groundwater levels. The increased downward head gradient during this period draws more recharge from standing water into available aquifer storage. This process of induced recharge from ponds and canals is widely observed in many regions with intensive groundwater pumping including the High Plains and the Mississippi Alluvial aquifer systems of the US as well as the Indus Basin (63-65).

Monthly groundwater hydrograph data from 1230 groundwater wells in Bangladesh from 2000-2013 supports the isotopic derived inference on the timing of groundwater recharge. Typically, groundwater levels are the lowest in April-May and highest in September-October. With these groundwater hydrographs, we considered rates of net discharge during the dry season (November to April) and rate of net recharge during the monsoon (April to October). During the dry season, the groundwater hydraulic head decreases rapidly from October to January $(>50 \%$ of the total decline in groundwater level) for most of the wells in response to natural discharge and groundwater abstraction (Figure S6A). Even though a large proportion of groundwater abstraction for dry season farming occurs between December and April (28), the decrease in head between February and April is smaller compared to the period from October to January (Figures S6B, S6C and $\mathrm{S} 6 \mathrm{D})$, suggesting that a portion of pumped water might be infiltrating back - a phenomena suggested by field experiments $(27,56)$. It is important to note that a falling water table does not imply that recharge is not occurring, but rather indicates that discharge is in excess of recharge at the time. Thus, during periods of high levels of discharge (e.g., during the irrigation season) total recharge may actually increase, while groundwater levels will nonetheless fall if discharge exceeds recharge. In fact, in the case of induced recharge from standing bodies of water, a falling water table will increase the downward head gradient and lead to greater recharge from standing water.

During the monsoon, the data suggests that most of the well experience their greatest hydraulic head increase between June and early August (Figure S7A and S7B) suggesting that a large proportion of net recharge happens during the early part of monsoon - thus, verifying the results obtained from the isotope mixing models. The head change in September is negligible (Figure S7C) across the country except in some northwestern parts which are experiencing longterm decline in groundwater level due to massive abstraction and reduction in precipitation (66, 67). The lack of rise in groundwater level in September suggests little recharge from precipitation. Similarly, in October, heads do not change for several wells suggesting even less recharge from precipitation as compared to the earlier months; for wells lying in the floodplains of Ganges and Brahmaputra the head in fact goes down as groundwater starts discharging to the river (Figure S7D).

\section{Regional model of shallow groundwater recharge}

Our analysis of the combined isotope data base supports a conceptual model of modern groundwater recharge in the Bengal Basin that divides groundwater recharge into three phases: (1) dry season (November-April), (2) early monsoon (May-August) and (3) late monsoon (September- 
October). These phases of the seasonal hydrologic cycle are similar to the results of Harvey et al., small-scale study (18) based on measured heads and water levels in one village. However, Harvey et al did not distinguish between recharge from precipitation and recharge from standing water, an important focus of this regional study. to rivers $(6,68,69)$ and the resulting increase in vertical head gradients draws more recharge from standing water into aquifers even as the water stored in aquifers decreases (Figure 9A). The proportion of recharge from different sources depends on several factors including water table drawdown, distance from rivers, patterns of hydraulic conductivity, and availability of standing water sources.

The depth of the dry season decline in the water table elevation has increased over recent decades because of groundwater extraction. For rice field irrigation, which makes up more than $85 \%$ of groundwater pumping (70), the amount of dry-season decline in the water table due to irrigation pumping is limited by the potential evaporation of rice fields. Groundwater pumped for irrigation circulates through rice fields, and what is not evapotranspired recharges the aquifer as return flow. Although drawdown is limited by the maximum rate of evapotranspiration, the rate of recharge from irrigated fields that returns to aquifers is not constrained and will increase with increasing rates of irrigation.

This circulation process can be formulated with a simple water balance: $\mathrm{Q}=\mathrm{RF}+\mathrm{ET}$, where $\mathrm{Q}$ is the extraction rate, $\mathrm{RF}$ is return flow, and ET is evapotranspiration, all in units of volume flux of water per unit area of rice field. The decline of the water table is $\mathrm{dH} / \mathrm{dt}=(\mathrm{Q}-\mathrm{FR}) / \mathrm{S}_{\mathrm{y}}=\mathrm{ET} / \mathrm{S}_{\mathrm{y}}$ where $S_{y}$ is the specific yield. This formulation assumes that irrigated fields are not simultaneously drained to rivers. Since rice is grown in standing water, and rice farming techniques used in the Bengal Basin are not the most efficient (71), a surplus of water (i.e. RF) recharges back to the aquifer. An important implication for groundwater isotopes is that enrichment may continue as groundwater is circulated. Over decades, groundwater may become progressively even more enriched in heavy isotopes as it is pumped to the surface, subjected to evaporation, and returned back to aquifers.

(2) During the early monsoon the unsaturated zone above the unconfined water table is filled by monsoon precipitation (Figure 9B). During this phase, maximum recharge by precipitation takes place, as evidenced from the distribution of precipitation isotope ratios estimated to be in groundwater by our model (Figure 8) and the rise in groundwater hydrographs (Figure 9). Independent analysis of groundwater hydrographs also suggests a rapid rise in groundwater levels during this period $(6,25)$. Recharge occurs across the entire basin and in some regions (such as northeast, Figure 9) maximum groundwater levels are observed during this time (6). Estimates of the mass of total water storage from GRACE and groundwater storage from wells during 2002-2010 $(72,73)$ indicate that on average $85 \%$ of the water is recharged by the end of July.

(3) In the late monsoon, groundwater recharge varies regionally, but is generally small. In eastern parts of Bangladesh (light green region in Figure S7) where shallow groundwater aquifers have already been recharged to a large extent during phase 2 the remaining space -if any-in the shallow aquifers is recharged in the early part of phase 3 (Figure 9C). Groundwater levels in the shallow aquifers in these regions are highest in August or early September (6). Precipitation and flooding events during this time do not recharge the aquifers and these waters are rejected as the shallow aquifers have already been filled. This region not only receives more precipitation than the western parts (Figure S1) of the basin, but also has a lower proportion of irrigated area that 
relies on groundwater (25). Other regions, mostly the western parts of Bangladesh and West Bengal, receive lower rainfall (Figure S1), are less prone to flooding, and are intensively farmed and pumped for irrigation (25). In these regions (shown in light gray in Figures S7C and S7D), where annual abstraction exceeds the groundwater recharge $(6,25,74)$, the aquifer continues to be recharged even during the late monsoon season.

\section{Implications for groundwater quantity, groundwater quality and human habitability}

Changes in the contribution from different sources suggests that the flow path of water entering the subsurface had changed. Large scale shifts in the flow paths would likely have major effects on the geochemistry of groundwater. Regional increases in contributions from ponds, rice fields, and rivers could threaten the regional quality of shallow groundwater. Circulating irrigation return flow may contaminate groundwater with increasing levels of solutes from rice field. Input of reactive organic carbon has been implicated in arsenic mobilization within aquifers $(17,18,55$, $75,76)$, although the source of this reactive carbon remains an area of active inquiry. Small-scale field studies have documented pollutants transported from ponds to drinking water wells (77-80), there is a growing concern of nitrate pollution in surface and groundwater (81), and local groundwater quality assessments have documented $E$. coli, major ions, trace elements and organic compounds $(82,83,92,84-91)$.

The Indian subcontinent accounts for more than $25 \%$ of the total global groundwater withdrawal and several aquifers are experiencing rapid declines in groundwater levels or reduction in groundwater quality $(84,85)$. A variety of studies in the subcontinent such as $(9,24,57,64,95-$ 97) has focused on understanding the rate of recharge and the chemical load carried in recharge, regional groundwater depletion and sources recharging groundwater, however a systematic analysis on the effect of large-scale pumping and dry-season farming on the timing and sources of recharge across the Indus-Ganges-Brahmaputra Basin is missing. Understanding how intensive groundwater pumping has affected, and will continue to affect, both the sources and timing of groundwater recharge is essential to understanding and managing the regional hydrologic system.

Our isotopic analysis provides evidence that across much of the eastern and southern Bengal Basin late monsoon precipitation does not recharge groundwater, likely because aquifers are full by August so that precipitation in September-October is lost as runoff. This "rejected potential recharge" was the focus of Roger Revelle's seminal paper (98) that promoted the idea of reducing monsoon flooding by pumping groundwater to lower the water table during the dry season so that more precipitation would infiltrate during the monsoon rather than contribute to flood water. Local hydrological modeling and field studies have arrived at a similar conclusion ( 6 , $24,25,99)$. Our isotope analysis suggest that increased pumping could be sustained in many parts of the basin where precipitation is sufficient to return the water table to the land surface every monsoon.

\section{Methods: Monte-Carlo Simulations}

\section{Model 1: Mixtures of precipitation and standing water}

We model groundwater isotope ratios as a mixture of precipitation and standing waters (i.e., ponds and rice fields):

$$
\delta^{18} O_{g w}=f_{\text {precip }} \delta^{18} O_{\text {precip }}+f_{\text {stand }} \delta^{18} O_{\text {stand }}
$$


$\delta^{2} H_{g w}=f_{\text {precip }} \delta^{2} H_{\text {precip }}+f_{\text {stand }} \delta^{2} H_{\text {stand }}$

where $\delta^{18} \mathrm{O}_{\mathrm{gw}}$ and $\delta^{2} \mathrm{H}_{\mathrm{gw}}$ are the isotope values of the groundwater, $\delta^{18} \mathrm{O}_{\text {precip }}$ and $\delta^{2} \mathrm{H}_{\text {precip }}$ are the isotope values of precipitation and $\delta^{18} \mathrm{O}_{\text {stand }}$ and $\delta^{2} \mathrm{H}_{\text {stand }}$ are the isotope values of the evaporated standing water bodies. $f_{\text {precip }}$ and $f_{\text {stand }}$ are the fractional contribution of precipitation and standing water to the groundwater and $f_{\text {precip }}+f_{\text {stand }}=1$.

We simulated all pairs of groundwater and standing water samples. We first obtain the $\delta^{18} \mathrm{O}_{\text {precip }}$ and $\delta^{2} \mathrm{H}_{\text {precip }}$ endmember values defined as the intersection between the local meteoric water line (LMWL) and the line joining the groundwater and the standing water sample in the dual isotope space (see Figure $5 \mathrm{~A}$ ). Then, $f_{\text {precip }}$ and $f_{\text {stand }}$ were calculated as:

$$
\begin{gathered}
f_{\text {precip }}=\frac{\delta^{18} O_{\text {precip }}-\delta^{18} O_{g w}}{\delta^{18} O_{g w}-\delta^{18} O_{\text {stand }}} \\
f_{\text {stand }}=1-f_{\text {precip }}
\end{gathered}
$$

After calculating the contribution of precipitation and standing water endmembers for each pair (Figure 5A), we calculated the mean to obtain the average contribution of precipitation and standing water endmembers respectively.

\section{Models 2 and 3: Mixtures of three recharge sources}

In the 3-endmember second and the third mixing models, we applied a Monte Carlo method $(36,100-103)$ to estimate probability distributions of the contributions of different sources recharging groundwater. This method entails more steps than model 1, that had only the two endmembers. The Monte Carlo simulations each draw from the large data set of precipitation and standing water isotope data to fully cover the probabilistic range of values as characterized by the available data.

Below, we describe the isotope values of each endmember. For the river endmember, we chose a fixed value $\left(\delta^{18} \mathrm{O}_{\mathrm{riv}}=-7.4 \%\right.$ and $\delta^{2} \mathrm{H}_{\mathrm{riv}}=-50 \%$ ), as the isotopic variation in the river values were negligible (Figure 4A). We calculated amount-weighted mean precipitation isotope ratios by weighting each sample by its proportional contribution to total annual precipitation. We assumed that precipitation isotope values follow a bivariate normal distribution with values $\left\{\mathrm{m}_{2}-\mathrm{H}, \mathrm{m}_{18-0}\right.$, $\left.\sigma_{2-\mathrm{H}}, \sigma_{18-\mathrm{O}}, \rho\right\}$ of $\{-46.5,-6.9,31.2,3.7,0.9\}$ where $\mathrm{m}_{2-\mathrm{H}}, \mathrm{m}_{18-0}, \sigma_{2-\mathrm{H}}, \sigma_{18-\mathrm{O}}$ are the amountweighted mean and standard deviation of the precipitation isotope values and $\rho$ is the correlation between the $\mathrm{O}$ and $\mathrm{H}$ precipitation isotopes. For the standing water endmember, we assumed that all the standing water samples included in this study $(n=447)$ are representative of the true distribution of the standing water isotope values and we treated each standing water isotope value as a potential endmember.

For each standing water sample, we simulated 500 random draws of precipitation isotope values to obtain precipitation endmember values. For each groundwater sample, we repeated the above process of simulating random draws of precipitation isotope values for each of the 447 standing water samples. In total, our approach generated $>200,000$ (447 standing water values multiplied by 500 precipitation values) possible "mixing triangles" for each groundwater sample.

For each combination of standing water, river and precipitation endmembers, where the endmember values were solvable $\left(0<=\left\{\mathrm{f}_{\text {precip }}, \mathrm{f}_{\text {riv }}, \mathrm{f}_{\text {stand }}\right\}<=1\right.$ and $\left.\mathrm{f}_{\text {precip }}+\mathrm{f}_{\text {riv }}+\mathrm{f}_{\text {stand }}=1\right)$, we obtained the fractional contribution of the endmembers (Figure 5B). When a groundwater sample fell outside the triangular domain ("mixing tringle") defined be the three end members (Figure 
$5 B$ ), we discarded this combination and did not calculate $f_{\text {precip }}, f_{\text {riv }}, f_{\text {stand }}$ as they would not fulfill the criteria: $0<=\left\{\mathrm{f}_{\text {precip }}, \mathrm{f}_{\text {riv }}, \mathrm{f}_{\text {stand }}\right\}<=1$. After calculating the contribution of precipitation, river and standing water endmembers for each solvable triangle (Figure 5), we calculated the mean to obtain the average contribution of precipitation, river and standing water endmembers respectively.

We only included groundwater samples that fell below the LMWL and were not highly evaporatively enriched. For groundwater samples, falling on or above the LMWL (14\% of the total groundwater sample), the contribution of surface water is minimal, and we assumed that the groundwater sample is completely recharged from precipitation i.e., $f_{\text {precip }}=1$ and $\mathrm{f}_{\text {stand }}=\mathrm{f}_{\text {riv }}=0$. Similarly, highly evaporated groundwater samples (deuterium excess $<0 \%$, $5 \%$ of the total groundwater sample) also typically fall outside the mixing triangle because the groundwater isotope ratios will have heavier isotope values than most of the standing water endmember values; this will result in only a small number of plausible mixing triangles. We assumed these evaporated samples to be recharged solely from standing water i.e., $f_{\text {stand }}=1$ and $f_{\text {riv }}=f_{\text {precip }}=0$. These assumptions are valid as it is very unlikely that samples falling above the LMWL are recharged by standing water. Similarly, highly evaporated groundwater samples are likely to be recharged primarily by standing water.

\section{Model 2: Mixtures of one precipitation event, river and standing water}

In the second model, we considered a 3 -endmember mixing model with precipitation, large rivers and standing water as the potential sources (Figure 5B). Groundwater sample isotope ratios $\left(\delta^{18} \mathrm{O}_{\mathrm{gw}}\right.$ and $\left.\delta^{2} \mathrm{H}_{\mathrm{gw}}\right)$ were modeled as a mixture of precipitation, river and standing waters endmembers:

$$
\begin{gathered}
\delta^{18} O_{g w}=f_{\text {precip }} \delta^{18} O_{\text {precip }}+f_{\text {riv }} \delta^{18} O_{\text {riv }}+f_{\text {stand }} \delta^{18} O_{\text {stand }} \\
\delta^{2} H_{g w}=f_{\text {precip }} \delta^{2} H_{\text {precip }}+f_{\text {riv }} \delta^{2} H_{\text {riv }}+f_{\text {stand }} \delta^{2} H_{\text {stand }}
\end{gathered}
$$

where $\delta^{18} \mathrm{O}_{\mathrm{gw}}$ and $\delta^{2} \mathrm{H}_{\mathrm{gw}}$ are the isotope values of the groundwater, $\delta^{18} \mathrm{O}_{\text {precip }}$ and $\delta^{2} \mathrm{H}_{\text {precip }}$ are the isotope values of precipitation, $\delta^{18}$ Oriv and $\delta^{2} \mathrm{H}_{\text {riv }}$ are the isotope values of the large rivers and $\delta^{18} \mathrm{O}_{\text {stand }}$ and $\delta^{2} \mathrm{H}_{\text {stand }}$ are the isotope values of the evaporated standing water bodies. $f_{\text {precip, }} f_{\text {riv }}$ and $f_{\text {stand }}$ are the fractional contribution of precipitation, large rivers and standing water to the groundwater and $f_{\text {precip }}+f_{\text {riv }}+f_{\text {stand }}=1$. After defining the isotope ratios of each endmember, we solve the above equations to obtain the fractional contributions of the endmembers $\left(f_{\text {river, }}, f_{\text {precip }}\right.$, and $f_{\text {stand.). }}$.

\section{Model 3: Mixtures of two precipitation events with standing water}

The third model consists of two precipitation and a standing water endmember (Figure 5C). In this model, groundwater isotope ratios were modeled as:

$$
\begin{gathered}
\delta^{18} O_{g w}=f_{\text {precip } 1} \delta^{18} O_{\text {precip } 1}+f_{\text {precip } 2} \delta^{18} O_{\text {precip } 2}+f_{\text {stand }} \delta^{18} O_{\text {stand }} \\
\delta^{2} H_{g w}=f_{\text {precip } 1} \delta^{2} H_{\text {precip } 1}+f_{\text {precip } 2} \delta^{2} H_{\text {precip } 2}+f_{\text {stand }} \delta^{2} H_{\text {stand }}
\end{gathered}
$$

where $\delta^{18} \mathrm{O}_{\mathrm{gw}}$ and $\delta^{2} \mathrm{H}_{\mathrm{gw}}$ are the isotope ratios of the groundwater, $\delta^{18} \mathrm{O}_{\text {precip1 }}$ and $\delta^{2} \mathrm{H}_{\text {precip1 }}$ and $\delta^{18} \mathrm{O}_{\text {precip2 }}$ and $\delta^{2} \mathrm{H}_{\text {precip2 }}$ are the isotope ratios of precipitation endmembers respectively. $f_{\text {precip } 1 \text {, }}$ $f_{\text {precip } 2}$ and $f_{\text {stand }}$ are the fractional contribution of precipitation and standing water to the groundwater and $f_{\text {precip } 1+,} f_{\text {precip } 2}+f_{\text {stand }}=1$. In this model, for each standing water endmember, we generate two distinct sets of 500 random precipitation isotope values, and from each set a random precipitation value is selected to obtain a pair of precipitation isotope ratios (Figure $5 \mathrm{C}$ ). We then 
613 solve the above equations to obtain the fractional contributions of the endmembers $\left(f_{\text {river, }}, f_{\text {precip } 2}\right.$ 614 and $f_{\text {stand.). }}$. 


\section{References}

616 1. A. M. MacDonald, H. C. Bonsor, K. M. Ahmed, W. G. Burgess, M. Basharat, R. C. Calow, A. Dixit, S. S. D. Foster, K. Gopal, D. J. Lapworth, R. M. Lark, M. Moench, A. Mukherjee, M. S. Rao, M. Shamsudduha, L. Smith, R. G. Taylor, J. Tucker, F. Van Steenbergen, S. K. Yadav, Groundwater quality and depletion in the Indo-Gangetic Basin mapped from in situ observations. Nat. Geosci. 9, 762-766 (2016).

2. K. M. Ahmed, P. Bhattacharya, M. A. Hasan, S. H. Akhter, S. M. M. Alam, M. A. H. Bhuyian, M. B. Imam, A. A. Khan, O. Sracek, Arsenic enrichment in groundwater of the alluvial aquifers in Bangladesh: An overview. Appl. Geochemistry. 19, 181-200 (2004).

3. H. A. Michael, C. I. Voss, Estimation of regional-scale groundwater flow properties in the Bengal Basin of India and Bangladesh. Hydrogeol. J. 17, 1329-1346 (2009).

4. M. R. Khan, M. Koneshloo, P. S. K. Knappett, K. M. Ahmed, B. C. Bostick, B. J. Mailloux, R. H. Mozumder, A. Zahid, C. F. Harvey, A. Van Geen, H. A. Michael, Megacity pumping and preferential flow threaten groundwater quality. Nat. Commun. 7, 1-8 (2016).

5. P. S. K. Knappett, B. J. Mailloux, I. Choudhury, M. R. Khan, H. A. Michael, S. Barua, D. R. Mondal, M. S. Steckler, S. H. Akhter, K. M. Ahmed, B. Bostick, C. F. Harvey, M. Shamsudduha, P. Shuai, I. Mihajlov, R. Mozumder, A. van Geen, Vulnerability of low-arsenic aquifers to municipal pumping in Bangladesh. J. Hydrol. 539, 674-686 (2016).

6. M. Shamsudduha, R. G. Taylor, K. M. Ahmed, A. Zahid, The impact of intensive groundwater abstraction on recharge to a shallow regional aquifer system: Evidence from Bangladesh. Hydrogeol. J. 19, 901-916 (2011).

7. M. Shamsudduha, R. G. Taylor, Groundwater storage dynamics in the world's large aquifer systems from GRACE: uncertainty and role of extreme precipitation. Earth Syst. Dyn. 11, 755774 (2020).

8. H. A. Michael, C. I. Voss, Evaluation of the sustainability of deep groundwater as an arsenic-safe resource in the Bengal Basin. Proc. Natl. Acad. Sci. U. S. A. 105, 8531-8536 (2008).

9. D. J. Lapworth, A. Zahid, R. G. Taylor, W. G. Burgess, M. Shamsudduha, K. M. Ahmed, A. Mukherjee, D. C. Gooddy, D. Chatterjee, A. M. MacDonald, Security of Deep Groundwater in the Coastal Bengal Basin Revealed by Tracers. Geophys. Res. Lett. 45, 8241-8252 (2018).

10. F. L. Naus, P. Schot, K. Groen, K. M. Ahmed, J. Griffioen, Groundwater salinity variation in Upazila Assasuni (southwestern Bangladesh), as steered by surface clay layer thickness, relative elevation and present-day land use. Hydrol. Earth Syst. Sci. 23, 1431-1451 (2019).

11. M. A. Mojid, M. F. Parvez, M. Mainuddin, G. Hodgson, Water Table Trend-A Sustainability Status of Groundwater Development in North-West Bangladesh. Water. 11, 1182 (2019).

12. S. Datta, A. W. Neal, T. J. Mohajerin, T. Ocheltree, B. E. Rosenheim, C. D. White, K. H. Johannesson, Geophys. Res. Lett., in press, doi:10.1029/2011GL049301.

13. S. Sengupta, J. M. Mcarthur, A. Sarkar, M. J. Leng, P. Ravenscroft, R. J. Howarth, D. M. Banerjee, Do ponds cause arsenic-pollution of groundwater in the Bengal Basin? An answer from West Bengal. Environ. Sci. Technol. 42, 5156-5164 (2008).

14. UNDP, Bangladesh : ground-water survey : the hydrogeologic conditions of Bangladesh : technical report :DP/UN/BGD-74-009/1 (1982).

15. R. K. Majumder, M. A. Halim, B. B. Saha, R. Ikawa, T. Nakamura, M. Kagabu, J. Shimada, Groundwater flow system in Bengal Delta, Bangladesh revealed by environmental isotopes. Environ. Earth Sci. 64, 1343-1352 (2011).

16. A. Biswas, H. Neidhardt, A. K. Kundu, D. Halder, D. Chatterjee, Z. Berner, G. Jacks, P. Bhattacharya, Spatial, vertical and temporal variation of arsenic in shallow aquifers of the Bengal Basin: Controlling geochemical processes. Chem. Geol. 387, 157-169 (2014).

17. R. B. Neumann, K. N. Ashfaque, A. B. M. Badruzzaman, M. Ashraf Ali, J. K. Shoemaker, C. F. Harvey, Anthropogenic influences on groundwater arsenic concentrations in Bangladesh. Nat. Geosci. 3, 46-52 (2010). 
665

666

667

668

669

670

671

672

673

674

675

676

677

678

679

680

681

682

683

684

685

686

687

688

689

690

691

692

693

694

695

696

697

698

699

700

701

702

703

704

705

706

707

708

709

710

711

712

713

714

715
18. C. F. Harvey, K. N. Ashfaque, W. Yu, A. B. M. Badruzzaman, M. A. Ali, P. M. Oates, H. A. Michael, R. B. Neumann, R. Beckie, S. Islam, M. F. Ahmed, Groundwater dynamics and arsenic contamination in Bangladesh. Chem. Geol. 228, 112-136 (2006).

19. M. O. Stahl, M. H. Tarek, D. C. J. Yeo, A. B. M. Badruzzaman, C. F. Harvey, Crab burrows as conduits for groundwater-surface water exchange in Bangladesh. Geophys. Res. Lett. 41, 83428347 (2014).

20. C. F. Harvey, Response to Comments on "Arsenic Mobility and Groundwater Extraction in Bangladesh." Science (80-. ). 300, 584d - 584 (2003).

21. R. Jakobsen, J. Kazmierczak, H. U. Sø, D. Postma, Water Resour. Res., in press, doi:10.1029/2018WR023685.

22. B. Weinman, S. L. Goodbred, Y. Zheng, Z. Aziz, M. Steckler, A. van Geen, A. K. Singhvi, Y. C. Nagar, Contributions of floodplain stratigraphy and evolution to the spatial patterns of groundwater arsenic in Araihazar, Bangladesh. Bull. Geol. Soc. Am. 120, 1567-1580 (2008).

23. J. Fergusson, On recent changes in the delta of the Ganges. Q. J. Geol. Soc. London. 19, 321-354 (1863).

24. S. Nowreen, R. G. Taylor, M. Shamsudduha, M. Salehin, A. Zahid, K. M. Ahmed, Groundwater recharge processes in an Asian mega-delta: hydrometric evidence from Bangladesh. Hydrogeol. J., $1-16$ (2020).

25. J. M. Kirby, M. D. Ahmad, M. Mainuddin, W. Palash, M. E. Quadir, S. M. Shah-Newaz, M. M. Hossain, The impact of irrigation development on regional groundwater resources in Bangladesh. Agric. Water Manag. 159, 264-276 (2015).

26. M. Mainuddin, M. Kirby, National food security in Bangladesh to 2050. Food Secur. 7, 633-646 (2015).

27. R. B. Neumann, M. L. Polizzotto, A. B. M. Badruzzaman, M. A. Ali, Z. Zhang, C. F. Harvey, Hydrology of a groundwater-irrigated rice field in Bangladesh: Seasonal and daily mechanisms of infiltration. Water Resour. Res. 45 (2009), doi:10.1029/2008WR007542.

28. M. Mainuddin, M. Kirby, R. A. R. Chowdhury, S. M. Shah-Newaz, Spatial and temporal variations of, and the impact of climate change on, the dry season crop irrigation requirements in Bangladesh. Irrig. Sci. 33, 107-120 (2015).

29. N. B. Jamil, H. Feng, K. M. Ahmed, I. Choudhury, P. Barnwal, A. Van Geen, Effectiveness of Different Approaches to Arsenic Mitigation over 18 Years in Araihazar, Bangladesh: Implications for National Policy. Environ. Sci. Technol. 53, 5596-5604 (2019).

30. B. Belton, A. Azad, The characteristics and status of pond aquaculture in Bangladesh. Aquaculture. 358-359 (2012), pp. 196-204.

31. I. Kränzlin, thesis, University of Basel (2000).

32. N. Huq, Small scale freshwater ponds in rural Bangladesh: Navigating roles and services. Int. J. Water. 11, 73-85 (2017).

33. B. J. Tipple, Y. Jameel, T. H. Chau, C. J. Mancuso, G. J. Bowen, A. Dufour, L. A. Chesson, J. R. Ehleringer, Stable hydrogen and oxygen isotopes of tap water reveal structure of the San Francisco Bay Area's water system and adjustments during a major drought. Water Res. 119 (2017), doi:10.1016/j.watres.2017.04.022.

34. Y. Jameel, S. Brewer, S. P. Good, B. J. Tipple, J. R. Ehleringer, G. J. Bowen, Tap water isotope ratios reflect urban water system structure and dynamics across a semiarid metropolitan area. Water Resour. Res. 52, 5891-5910 (2016).

35. J. Evaristo, S. Jasechko, J. J. McDonnell, Global separation of plant transpiration from groundwater and streamflow. Nature. 525, 91-94 (2015).

36. G. J. Bowen, A. Putman, J. R. Brooks, D. R. Bowling, E. J. Oerter, S. P. Good, Inferring the source of evaporated waters using stable H and O isotopes. Oecologia. 187, 1025-1039 (2018).

37. S. Fendorf, H. A. Michael, A. Van Geen, Spatial and temporal variations of groundwater arsenic in South and Southeast Asia. Science (80-. ). 328 (2010), pp. 1123-1127.

38. M. O. Stahl, J. B. Ong, C. F. Harvey, C. D. Johnson, A. B. M. Badruzzaman, M. H. Tarek, A. van 
39. I. Choudhury, K. M. Ahmed, M. Hasan, M. R. H. Mozumder, P. S. K. Knappett, T. Ellis, A. van Geen, Evidence for Elevated Levels of Arsenic in Public Wells of Bangladesh Due To Improper Installation. Groundwater. 54, 871-877 (2016).

40. S. Sengupta, A. Sarkar, Stable isotope evidence of dual (Arabian Sea and Bay of Bengal) vapour sources in monsoonal precipitation over north India. Earth Planet. Sci. Lett. 250, 511-521 (2006).

41. N. C. Munksgaard, N. Kurita, R. Sánchez-Murillo, N. Ahmed, L. Araguas, D. L. Balachew, M. I. Bird, S. Chakraborty, N. Kien Chinh, K. M. Cobb, S. A. Ellis, G. Esquivel-Hernández, S. Y. Ganyaglo, J. Gao, D. Gastmans, K. F. Kaseke, S. Kebede, M. R. Morales, M. Mueller, S. C. Poh, V. dos Santos, H. Shaoneng, L. Wang, H. Yacobaccio, C. Zwart, Data Descriptor: Daily observations of stable isotope ratios of rainfall in the tropics. Sci. Rep. 9 (2019), doi:10.1038/s41598-019-50973-9.

42. B. Kumar, S. P. Rai, U. S. Kumar, S. K. Verma, P. Garg, S. V. V. Kumar, R. Jaiswal, B. K. Purendra, S. R. Kumar, N. G. Pande, Isotopic characteristics of Indian precipitation. Water Resour. Res. 46 (2010), doi:10.1029/2009WR008532.

43. M. Tanoue, K. Ichiyanagi, K. Yoshimura, M. Kiguchi, T. Terao, T. Hayashi, Seasonal variation in isotopic composition and the origin of precipitation over Bangladesh. Prog. Earth Planet. Sci. 5, $1-16(2018)$.

44. J. M. McArthur, U. Ghosal, P. K. Sikdar, J. D. Ball, Arsenic in Groundwater: The Deep Late Pleistocene Aquifers of the Western Bengal Basin. Environ. Sci. Technol. 50, 3469-3476 (2016).

45. I. Mihajlov, M. Stute, P. Schlosser, B. J. Mailloux, Y. Zheng, I. Choudhury, K. M. Ahmed, A. van Geen, Recharge of low-arsenic aquifers tapped by community wells in Araihazar, Bangladesh, inferred from environmental isotopes. Water Resour. Res. 52, 3324-3349 (2016).

46. A. Van Geen, E. B. Ahmed, L. Pitcher, J. L. Mey, H. Ahsan, J. H. Graziano, K. M. Ahmed, Comparison of two blanket surveys of arsenic in tubewells conducted 12 years apart in a $25 \mathrm{~km} 2$ area of Bangladesh. Sci. Total Environ. 488-489, 484-492 (2014).

47. A. H. A. N. Khan, M. A. Q. Bhuyian, M. A. Ahsan, F. Islam, M. M. Karim, M. Moniruzzaman, in Water, Flood Management and Water Security Under a Changing Climate (Springer International Publishing, 2020; https://doi.org/10.1007/978-3-030-47786-8_1), pp. 1-14.

48. A. Kumar, P. Sanyal, S. Agrawal, Spatial distribution of $\delta 18 \overline{\mathrm{O}}$ values of water in the Ganga river basin: Insight into the hydrological processes. J. Hydrol. 571, 225-234 (2019).

49. L. Lambs, K. Balakrishna, F. Brunet, J. L. Probst, Oxygen and hydrogen isotopic composition of major Indian rivers: a first global assessment. Hydrol. Process. 19, 3345-3355 (2005).

50. J. J. Gibson, S. J. Birks, T. W. D. Edwards, Global Biogeochem. Cycles, in press, doi:10.1029/2007GB002997.

51. A. Mukherjee, S. N. Bhanja, Y. Wada, Groundwater depletion causing reduction of baseflow triggering Ganges river summer drying. Sci. Rep. 8, 1-9 (2018).

52. P. Aggarwal, A. Basu, J. P. Robert, K. Kulkarni, S. Tarafdar, M. Ali, N. Ahmed, A. Hussain, M. Rahman, S. Reazuddin Ahmed, “A Report on Isotope Hydrology of Groundwater in Bangladesh: Implications for Characterization and Mitigation of Arsenic in Groundwater Work Performed within an IAEA-TC Project (BGD/8/016)" (2000).

53. P. Ravenscroft, J. M. McArthur, M. S. Rahman, Identifying multiple deep aquifers in the Bengal Basin: Implications for resource management. Hydrol. Process. 32, 3615-3632 (2018).

54. A. Mukherjee, A. E. Fryar, P. D. Howell, Regional hydrostratigraphy and groundwater flow modeling in the arsenic-affected areas of the western Bengal basin, West Bengal, India. Hydrogeol. J. 15, 1397-1418 (2007).

55. M. Lawson, D. A. Polya, A. J. Boyce, C. Bryant, D. Mondal, A. Shantz, C. J. Ballentine, Pondderived organic carbon driving changes in arsenic hazard found in asian groundwaters. Environ. Sci. Technol. 47, 7085-7094 (2013).

56. A. S. Qureshi, Z. U. Ahmed, T. J. Krupnik, "Groundwater management in Bangladesh: An 
57. M. O. Stahl, A. B. M. Badruzzaman, M. H. Tarek, C. F. Harvey, Geochemical transformations beneath man-made ponds: Implications for arsenic mobilization in South Asian aquifers. Geochim. Cosmochim. Acta. 288, 262-281 (2020).

58. H. A. Michael, C. I. Voss, Estimation of regional-scale groundwater flow properties in the Bengal Basin of India and Bangladesh. Hydrogeol. J. 17, 1329-1346 (2009).

59. I. Clark, P. Fritz, Environmental isotopes in hydrogeology (1997).

60. S. Jasechko, Global Isotope Hydrogeology-Review. Rev. Geophys. 57 (2019), pp. 835-965.

61. M. O. Stahl, J. Gehring, Y. Jameel, Hydrol. Process., in press, doi:10.1002/hyp.13832.

62. S. Jasechko, R. G. Taylor, Intensive rainfall recharges tropical groundwaters. Environ. Res. Lett. 10, 124015 (2015).

63. M. Cherry, T. Gilmore, A. Mittelstet, D. Gastmans, V. Santos, J. B. Gates, Recharge seasonality based on stable isotopes: Nongrowing season bias altered by irrigation in Nebraska. Hydrol. Process. 34, 1575-1586 (2020).

64. S. K. Joshi, S. P. Rai, R. Sinha, S. Gupta, A. L. Densmore, Y. S. Rawat, S. Shekhar, Tracing groundwater recharge sources in the northwestern Indian alluvial aquifer using water isotopes ( $\delta 18 \mathrm{O}, \delta 2 \mathrm{H}$ and $3 \mathrm{H})$. J. Hydrol. 559, 835-847 (2018).

65. M. C. Gratzer, G. R. Davidson, A. M. O’Reilly, J. R. Rigby, Groundwater recharge from an oxbow lake-wetland system in the Mississippi Alluvial Plain. Hydrol. Process. 34, 1359-1370 (2020).

66. K. Alam, Farmers' adaptation to water scarcity in drought-prone environments: A case study of Rajshahi District, Bangladesh. Agric. Water Manag. 148, 196-206 (2015).

67. A. S. Rahman, M. Kamruzzama, C. S. Jahan, Q. H. Mazumder, Long-term trend analysis of water table using 'MAKESENS' model and sustainability of groundwater resources in drought prone Barind area, NW Bangladesh. J. Geol. Soc. India. 87, 179-193 (2016).

68. M. R. H. Mozumder, H. A. Michael, I. Mihajlov, M. R. Khan, P. S. K. Knappett, B. C. Bostick, B. J. Mailloux, K. M. Ahmed, I. Choudhury, T. Koffman, T. Ellis, K. Whaley-Martin, R. San Pedro, G. Slater, M. Stute, P. Schlosser, A. Geen, Origin of Groundwater Arsenic in a Rural Pleistocene Aquifer in Bangladesh Depressurized by Distal Municipal Pumping. Water Resour. Res. 56 (2020), doi:10.1029/2020WR027178.

69. P. K. Sikdar, S. Chakraborty, Numerical modelling of groundwater flow to understand the impacts of pumping on arsenic migration in the aquifer of North Bengal Plain. J. Earth Syst. Sci. 126, 29 (2017).

70. S. Bhattacharjee, B. Saha, B. Saha, M. S. Uddin, C. H. Panna, P. Bhattacharya, R. Saha, Groundwater governance in Bangladesh: Established practices and recent trends. Groundw. Sustain. Dev. 8, 69-81 (2019).

71. S. I. Bhuiyan, M. A. Sattar, M. A. K. Khan, Improving water use efficiency in rice irrigation through wet-seeding. Irrig. Sci. 16, 1-8 (1995).

72. M. S. Steckler, S. L. Nooner, S. H. Akhter, S. K. Chowdhury, S. Bettadpur, L. Seeber, M. G. Kogan, Modeling Earth deformation from monsoonal flooding in Bangladesh using hydrographic, GPS, and Gravity Recovery and Climate Experiment (GRACE) data. J. Geophys. Res. 115, B08407 (2010).

73. M. Steckler, D. R. Mondal, S. L. Nooner, S. H. Akhter, L. Seeber, S. V. Bettadpur, C. Sazedul Karim, M. Howe, F. Masson, T. Maurin, C. Rangin, Modeling Earth deformation from monsoonal flooding in Bangladesh using hydrographic, GPS, and Gravity Recovery and Climate Experiment (GRACE) data - Steckler - 2010 - Journal of Geophysical Research: Solid Earth - Wiley Online Library. $A G U$ (2013), (available at https://agupubs.onlinelibrary.wiley.com/doi/pdf/10.1029/2009JB007018).

74. M. Shamsudduha, R. E. Chandler, R. G. Taylor, K. M. Ahmed, Recent trends in groundwater levels in a highly seasonal hydrological system: the Ganges-Brahmaputra-Meghna Delta. Hydrol. 
Earth Syst. Sci. 13, 2373-2385 (2009).

75. C. F. Harvey, C. H. Swartz, A. B. M. Badruzzaman, N. Keon-Blute, W. Yu, M. A. Ali, J. Jay, R. Beckie, V. Niedan, D. Brabander, P. M. Oates, K. N. Ashfaque, S. Islam, H. F. Hemond, M. F. Ahmed, Arsenic mobility and groundwater extraction in Bangladesh. Science (80-. ). 298, 16021606 (2002).

76. B. J. Mailloux, E. Trembath-Reichert, J. Cheung, M. Watson, M. Stute, G. A. Freyer, A. S. Ferguson, K. M. Ahmed, M. J. Alam, B. A. Buchholz, J. Thomas, A. C. Layton, Y. Zheng, B. C. Bostick, A. Van Geen, Advection of surface-derived organic carbon fuels microbial reduction in Bangladesh groundwater. Proc. Natl. Acad. Sci. U. S. A. 110, 5331-5335 (2013).

77. P. S. K. Knappett, V. Escamilla, A. Layton, L. D. McKay, M. Emch, D. E. Williams, R. Huq, J. Alam, L. Farhana, B. J. Mailloux, A. Ferguson, G. S. Sayler, K. M. Ahmed, A. van Geen, Impact of population and latrines on fecal contamination of ponds in rural Bangladesh. Sci. Total Environ. 409, 3174-3182 (2011).

78. A. Van Geen, K. M. Ahmed, Y. Akita, M. J. Alam, P. J. Culligan, M. Emch, V. Escamilla, J. Feighery, A. S. Ferguson, P. Knappett, A. C. Layton, B. J. Mailloux, L. D. McKay, J. L. Mey, M. L. Serre, P. K. Streatfield, J. Wu, M. Yunus, Fecal contamination of shallow tubewells in Bangladesh inversely related to arsenic. Environ. Sci. Technol. 45, 1199-1205 (2011).

79. P. S. K. Knappett, L. D. McKay, A. Layton, D. E. Williams, M. J. Alam, M. R. Huq, J. Mey, J. E. Feighery, P. J. Culligan, B. J. Mailloux, J. Zhuang, V. Escamilla, M. Emch, E. Perfect, G. S. Sayler, K. M. Ahmed, A. Van Geen, Implications of fecal bacteria input from latrine-polluted ponds for wells in sandy aquifers. Environ. Sci. Technol. 46, 1361-1370 (2012).

80. V. Escamilla, P. S. K. Knappett, M. Yunus, P. K. Streatfield, M. Emch, Influence of Latrine Proximity and Type on Tubewell Water Quality and Diarrheal Disease in Bangladesh. https://doi.org/10.1080/00045608.2013.756257 (2013), doi:10.1080/00045608.2013.756257.

81. R. K. Majumder, M. A. Hasnat, S. Hossain, K. Ikeue, M. Machida, An exploration of nitrate concentrations in groundwater aquifers of central-west region of Bangladesh. J. Hazard. Mater. 159, 536-543 (2008).

82. M. A. Akber, M. A. Islam, M. Dutta, S. M. Billah, M. A. Islam, Nitrate contamination of water in dug wells and associated health risks of rural communities in southwest Bangladesh. Environ. Monit. Assess. 192, 1-12 (2020).

83. M. S. Bhuyan, M. A. Bakar, A. Akhtar, M. B. Hossain, M. M. Ali, M. S. Islam, Heavy metal contamination in surface water and sediment of the Meghna River, Bangladesh. Environ. Nanotechnology, Monit. Manag. 8, 273-279 (2017).

84. M. S. Islam, M. K. Ahmed, M. Habibullah-Al-Mamun, M. F. Hoque, Preliminary assessment of heavy metal contamination in surface sediments from a river in Bangladesh. Environ. Earth Sci. 73, 1837-1848 (2015).

85. M. S. Islam, M. B. Hossain, A. Matin, M. S. Islam Sarker, Assessment of heavy metal pollution, distribution and source apportionment in the sediment from Feni River estuary, Bangladesh. Chemosphere. 202, 25-32 (2018).

86. M. Rahman, M. Bodrud-Doza, M. Muhib, M. Sikder, M. Shammi, R. Akter, M. Uddin, Human Health Risk Assessment of Nitrate and Trace Metals Via Groundwater in Central Bangladesh. Pollution. 6, 253-266 (2020).

87. L. Benneyworth, J. Gilligan, J. C. Ayers, S. Goodbred, G. George, A. Carrico, M. R. Karim, F. Akter, D. Fry, K. Donato, B. Piya, Drinking water insecurity: water quality and access in coastal south-western Bangladesh. Int. J. Environ. Health Res. 26, 508-524 (2016).

88. J. M. McArthur, P. K. Sikdar, M. A. Hoque, U. Ghosal, Waste-water impacts on groundwater: $\mathrm{Cl} / \mathrm{Br}$ ratios and implications for arsenic pollution of groundwater in the Bengal Basin and Red River Basin, Vietnam. Sci. Total Environ. 437, 390-402 (2012).

89. M. A. H. Bhuiyan, M. Bodrud-Doza, A. R. M. T. Islam, M. A. Rakib, M. S. Rahman, A. L. Ramanathan, Assessment of groundwater quality of Lakshimpur district of Bangladesh using water quality indices, geostatistical methods, and multivariate analysis. Environ. Earth Sci. 75, 1- 
90. A. R. M. T. Islam, N. Ahmed, M. Bodrud-Doza, R. Chu, Characterizing groundwater quality ranks for drinking purposes in Sylhet district, Bangladesh, using entropy method, spatial autocorrelation index, and geostatistics. Environ. Sci. Pollut. Res. 24, 26350-26374 (2017).

91. A. Das, S. S. Das, N. R. Chowdhury, M. Joardar, B. Ghosh, T. Roychowdhury, Quality and health risk evaluation for groundwater in Nadia district, West Bengal: An approach on its suitability for drinking and domestic purpose. Groundw. Sustain. Dev. 10, 100351 (2020).

92. S. K. Mandal, S. K. Dutta, S. Pramanik, R. K. Kole, Assessment of river water quality for agricultural irrigation. Int. J. Environ. Sci. Technol. 16, 451-462 (2019).

93. A. Asoka, T. Gleeson, Y. Wada, V. Mishra, Relative contribution of monsoon precipitation and pumping to changes in groundwater storage in India. Nat. Geosci. 10, 109-117 (2017).

94. W. Aeschbach-Hertig, T. Gleeson, Regional strategies for the accelerating global problem of groundwater depletion. Nat. Geosci. 5 (2012), pp. 853-861.

95. D. J. Lapworth, A. M. MacDonald, G. Krishan, M. S. Rao, D. C. Gooddy, W. G. Darling, Groundwater recharge and age-depth profiles of intensively exploited groundwater resources in northwest India. Geophys. Res. Lett. 42, 7554-7562 (2015).

96. T. Keesari, D. A. Sharma, M. S. Rishi, D. Pant, H. V. Mohokar, A. K. Jaryal, U. K. Sinha, Isotope investigation on groundwater recharge and dynamics in shallow and deep alluvial aquifers of southwest Punjab. Appl. Radiat. Isot. 129, 163-170 (2017).

97. N. Mushtaq, A. Younas, A. Mashiatullah, T. Javed, A. Ahmad, A. Farooqi, Hydrogeochemical and isotopic evaluation of groundwater with elevated arsenic in alkaline aquifers in Eastern Punjab, Pakistan. Chemosphere. 200, 576-586 (2018).

98. R. Revelle, V. Lakshminarayana, The Ganges water machine. Science (80-. ). 188, 611-616 (1975).

99. M. R. Khan, C. I. Voss, W. Yu, H. A. Michael, Water Resources Management in the Ganges Basin: A Comparison of Three Strategies for Conjunctive Use of Groundwater and Surface Water. Water Resour. Manag. 28, 1235-1250 (2014).

100. Y. Jameel, S. Brewer, R. P. Fiorella, B. J. Tipple, S. Terry, G. J. Bowen, Isotopic reconnaissance of urban water supply system dynamics. Hydrol. Earth Syst. Sci. 22 (2018), doi:10.5194/hess-226109-2018.

101. A. A. Nghiem, M. O. Stahl, B. J. Mailloux, T. T. Mai, P. T. Trang, P. H. Viet, C. F. Harvey, A. Geen, B. C. Bostick, Quantifying Riverine Recharge Impacts on Redox Conditions and Arsenic Release in Groundwater Aquifers Along the Red River, Vietnam. Water Resour. Res. 55, 6712 6728 (2019).

102. J. J. Follstad Shah, Y. Jameel, R. M. Smith, R. S. Gabor, P. D. Brooks, S. R. Weintraub, Spatiotemporal Variability in Water Sources Controls Chemical and Physical Properties of a Semi-arid Urban River System. J. Am. Water Resour. Assoc. 55, 591-607 (2019).

103. J. Cable, K. Ogle, D. Williams, Contribution of glacier meltwater to streamflow in the Wind River Range, Wyoming, inferred via a Bayesian mixing model applied to isotopic measurements. Hydrol. Process. 25, 2228-2236 (2011).

104. M. A. Hoque, W. G. Burgess, 14C dating of deep groundwater in the Bengal Aquifer System, Bangladesh: Implications for aquifer anisotropy, recharge sources and sustainability. J. Hydrol. 444-445, 209-220 (2012).

\section{Data Availability}

Data analyzed in this paper are publicly available and the references are provided in the supplementary information. New data included in this analyzed are included in the supplementary information. Groundwater hydrograph data is available upon request. 


\section{Acknowledgment}

919 We thank Andrew Desbarats, Geological Survey of Canada, Natural Resources Canada, 920 Ottawa, Canada, and Tanoue Masahiro, Shibura Institute of Technology, Japan for sharing their 921 research data with us. Funding: This work was supported by a grant from the USGS Powell

922 Centre for Analysis and Synthesis and the Abdul Latif Jameel Water and Food Systems Lab (J923 WAFS), MIT. Author contributions: YJ and CH formulated the research, YJ, CH and MS 924 designed the analyses, YJ conducted the analyses and wrote the manuscript. All the authors 925 analyzed the result and edited the manuscript. Competing interests: The authors declare no 926 competing interests. 


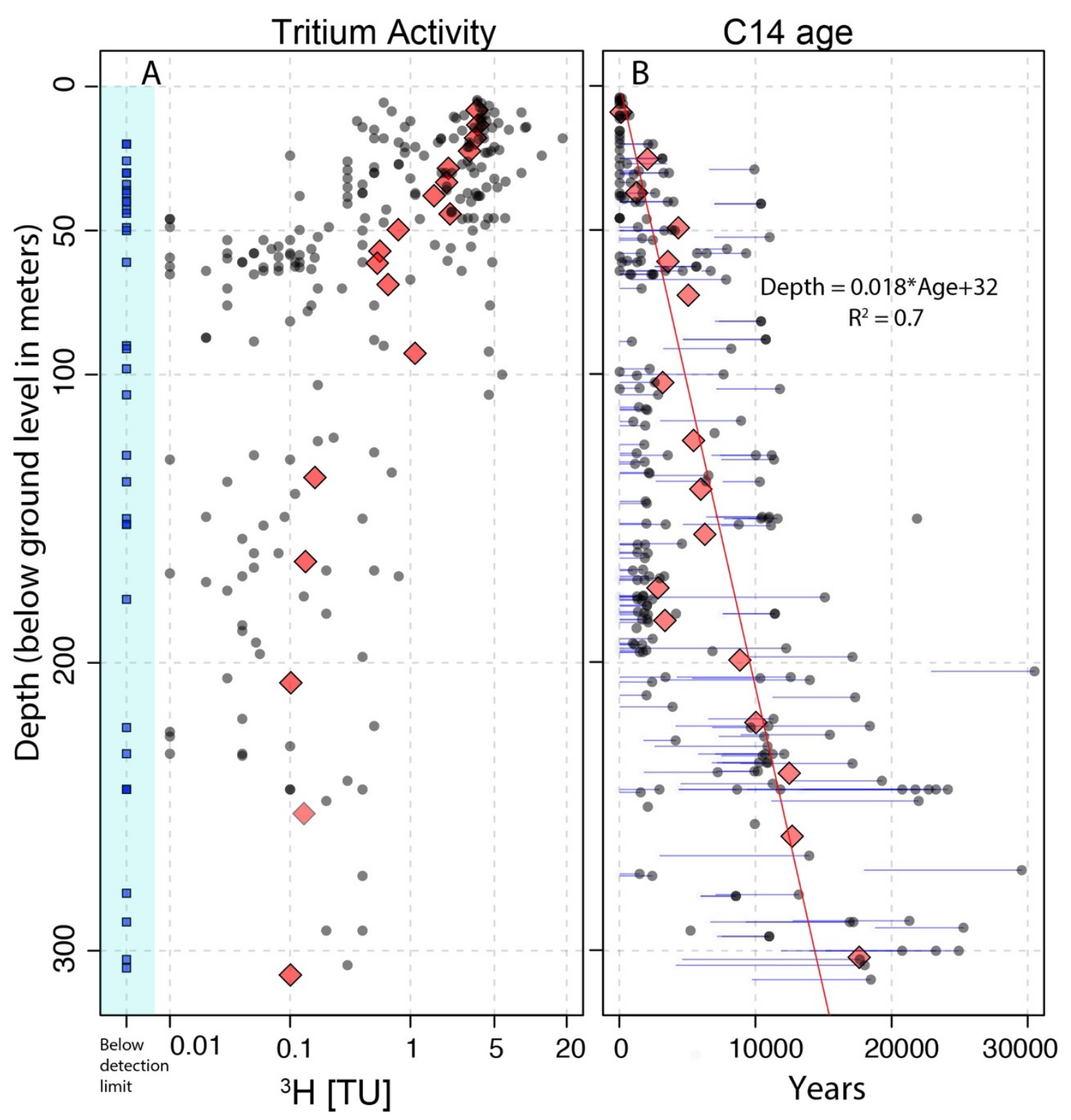

Figure 1: Tritium activity and $14 \mathrm{C}$ ages at different depths from across the Bengal Basin. Tritium activity (A) and uncorrected groundwater C14 ages (B) shown in black circles. The red diamonds represent average over 15 measurements. Blue squares in panel A are values below detection limit, which varies from study to study (Table S2). The horizontal lines in panel B represent corrected ages after accounting for radiocarbon-dead dissolved inorganic carbon using the method described in reference (104). Red line in panel B is the best fit line to the depth averaged C14 ages (red diamonds). See tables S2 and S3 for data source. 

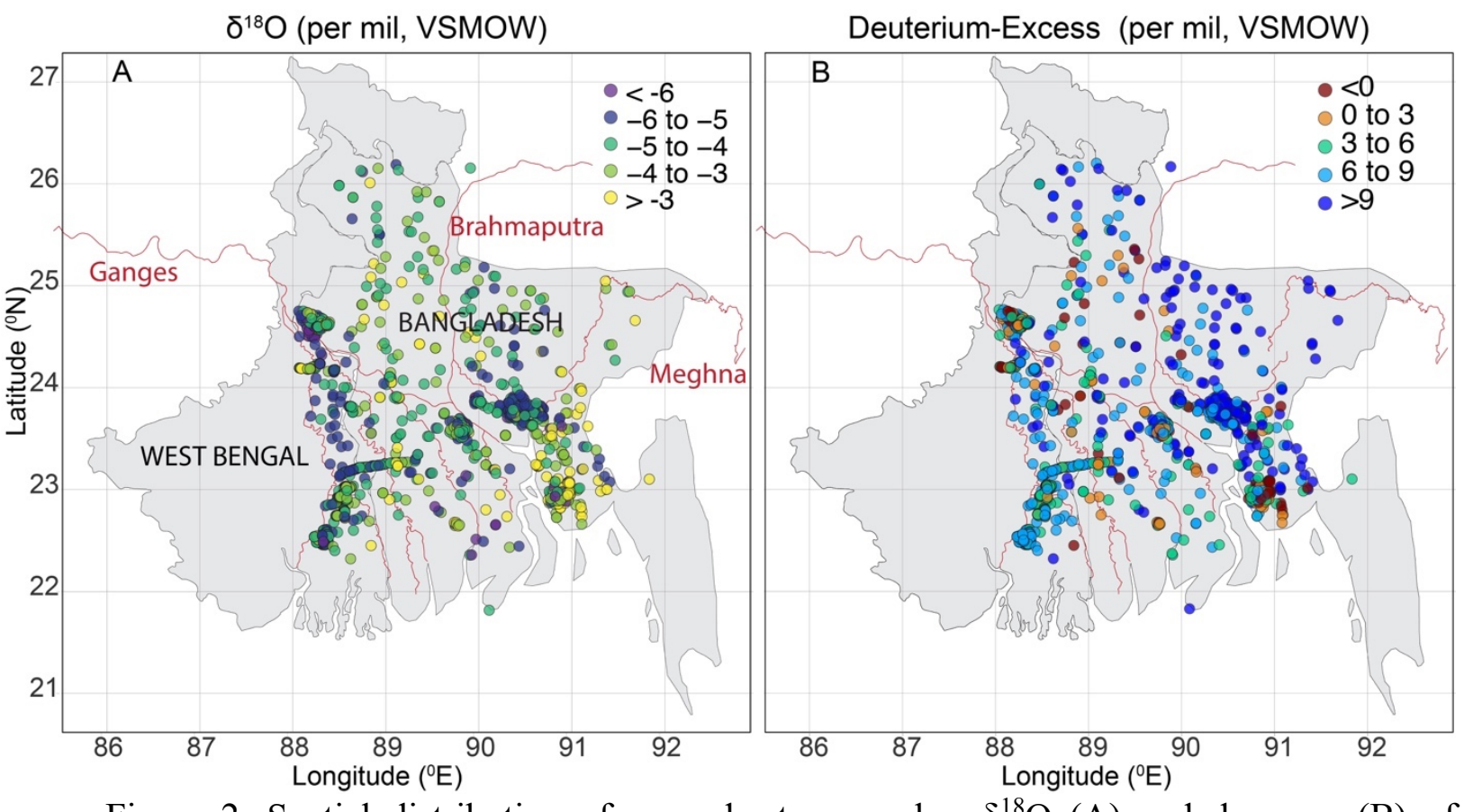

Figure 2: Spatial distribution of groundwater samples. $\delta^{18} \mathrm{O}(\mathrm{A})$ and d-excess (B) of georeferenced groundwater samples (circles) across the Bengal basin (Bangladesh and West Bengal, India). The three major rivers Ganges, Brahmaputra and Meghna and their tributaries are shown in red lines. Samples that were not georeferenced but included in the mixing model analysis have not been shown here. Groundwater $\delta^{18} \mathrm{O}$ and d-excess values across the basin were not spatially correlated (Moran's I statistics was 0.18 and $0.11, \mathrm{p}<0.005$ for $\delta^{18} \mathrm{O}$ and d-excess respectively). 

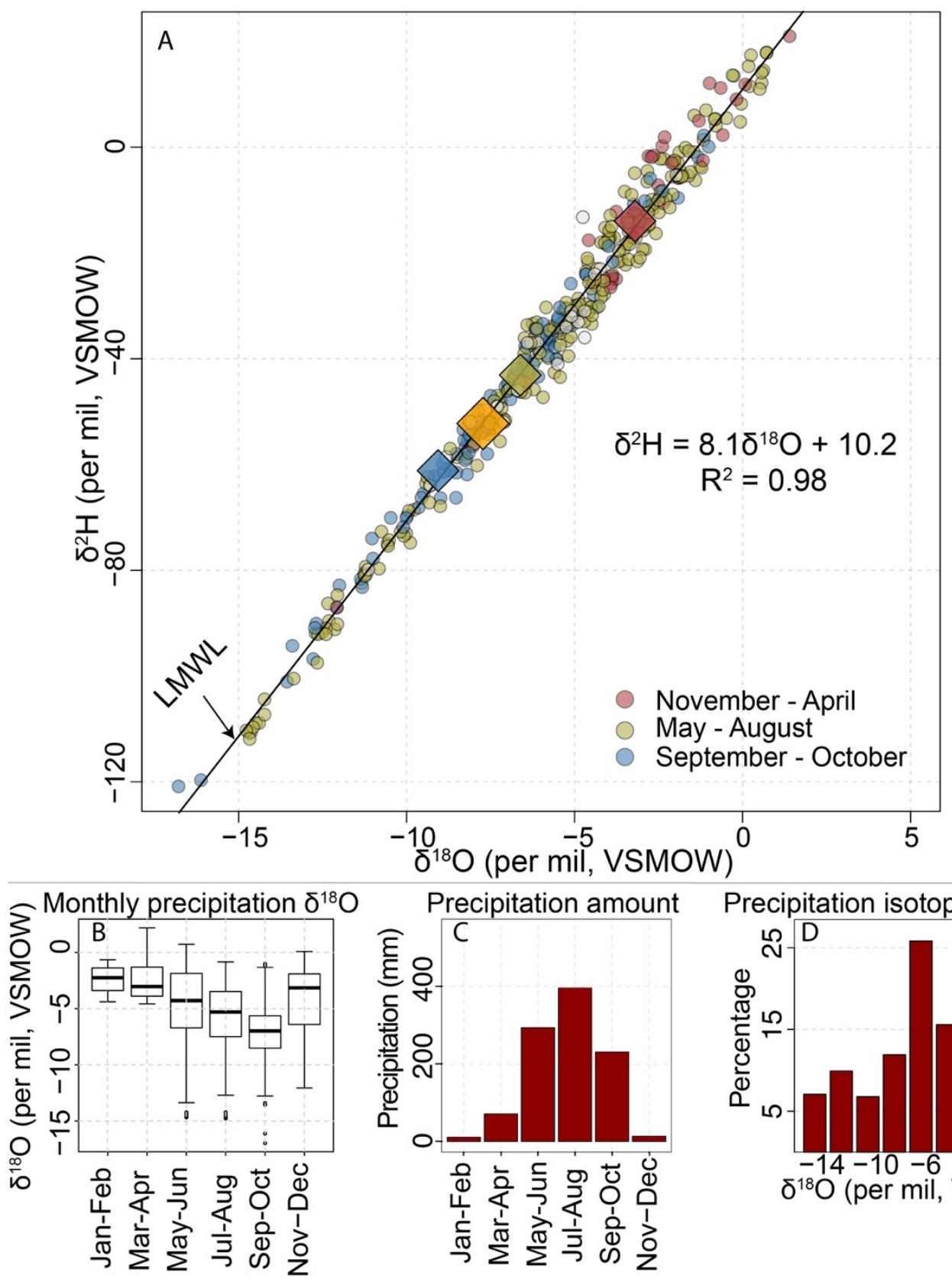

Precipitation isotopic proportion

Figure 3: Precipitation isotope ratios in the Bengal Basin. (A) Precipitation stable isotope values from Bengal basin. Black line is the local meteoric water line (LMWL). Precipitation samples collected in dry months (November - May), early monsoon (June - July) and late monsoon (August - October) are colored red, green and blue respectively. The orange diamond is the amount-weighted mean precipitation isotope value for the Bengal Basin. The red, green and blue diamonds are the amount-weighted mean precipitation isotope values for dry season, early monsoon and late monsoon seasons. (B) Monthly precipitation $\delta^{18} \mathrm{O}$ values. (C) Average precipitation amount. (D) Proportion of rainfall amount grouped by their isotopic composition. Please refer to Figure S1 and S2 for spatial pattern in precipitation amount and precipitation $\delta^{18} \mathrm{O}$ values. 

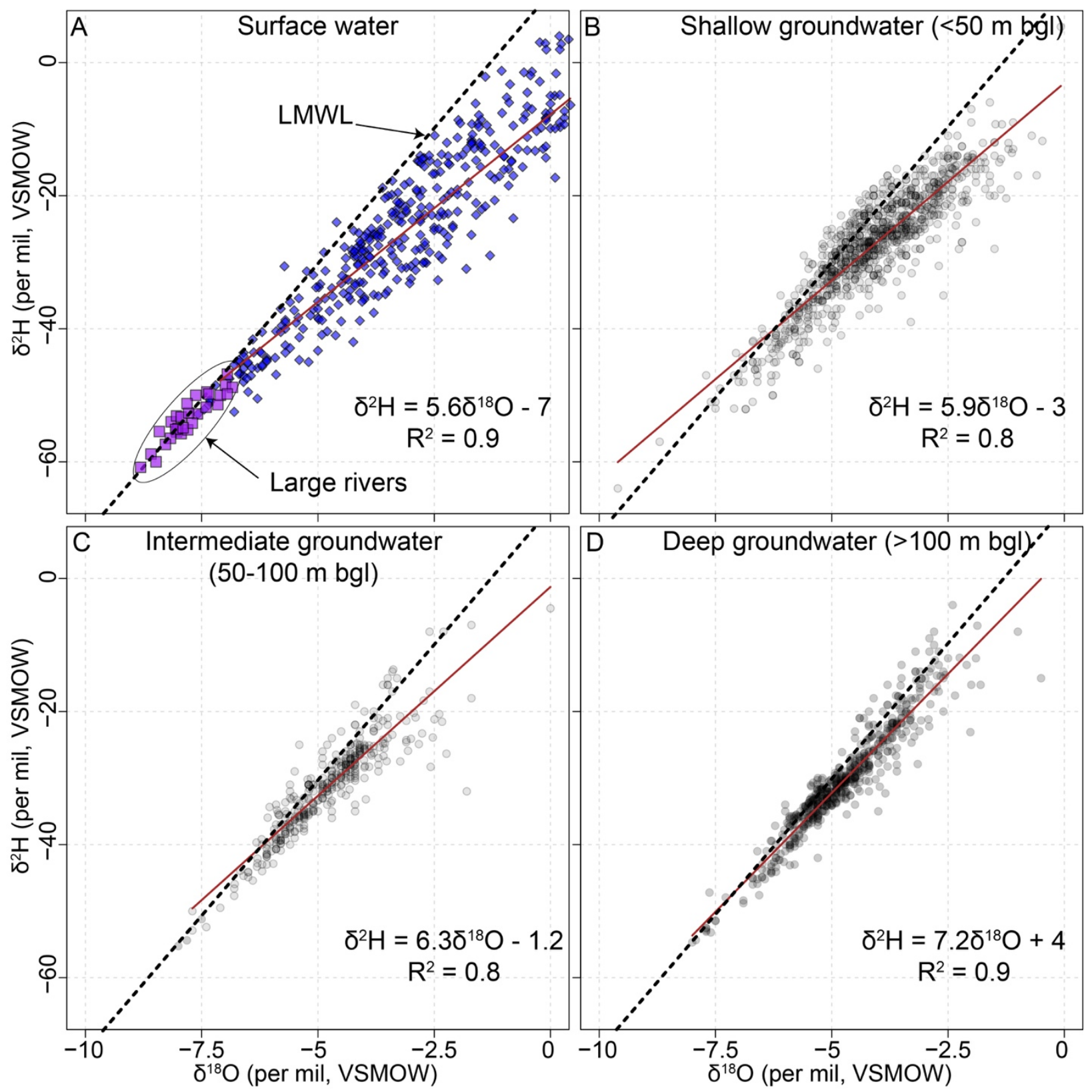

Figure 4: Surface and groundwater isotope ratios. Stable isotope values of surface water (A), shallow (B), intermediate (C) and deep (D) wells in the Bengal Basin The local evaporation line (LEL) for surface water (A) is shown in brown line. Purple squares and blue diamonds in panel (A) are the isotope ratios of large rivers and standing water respectively Dark red line in panels (A-D) are the respective groundwater lines for shallow, intermediate and deep wells. The equations are the best fit evaporation line (panel A) and groundwater lines (panels B-D). Black dashed line in each panel is the LMWL. For clarity, very enriched standing and groundwater 966 samples $\left(\delta^{18} \mathrm{O}>0 \%\right.$ ) and depleted river samples $\left(\delta^{18} \mathrm{O}<-10 \%\right.$ ) have been removed from the 967 figure. 

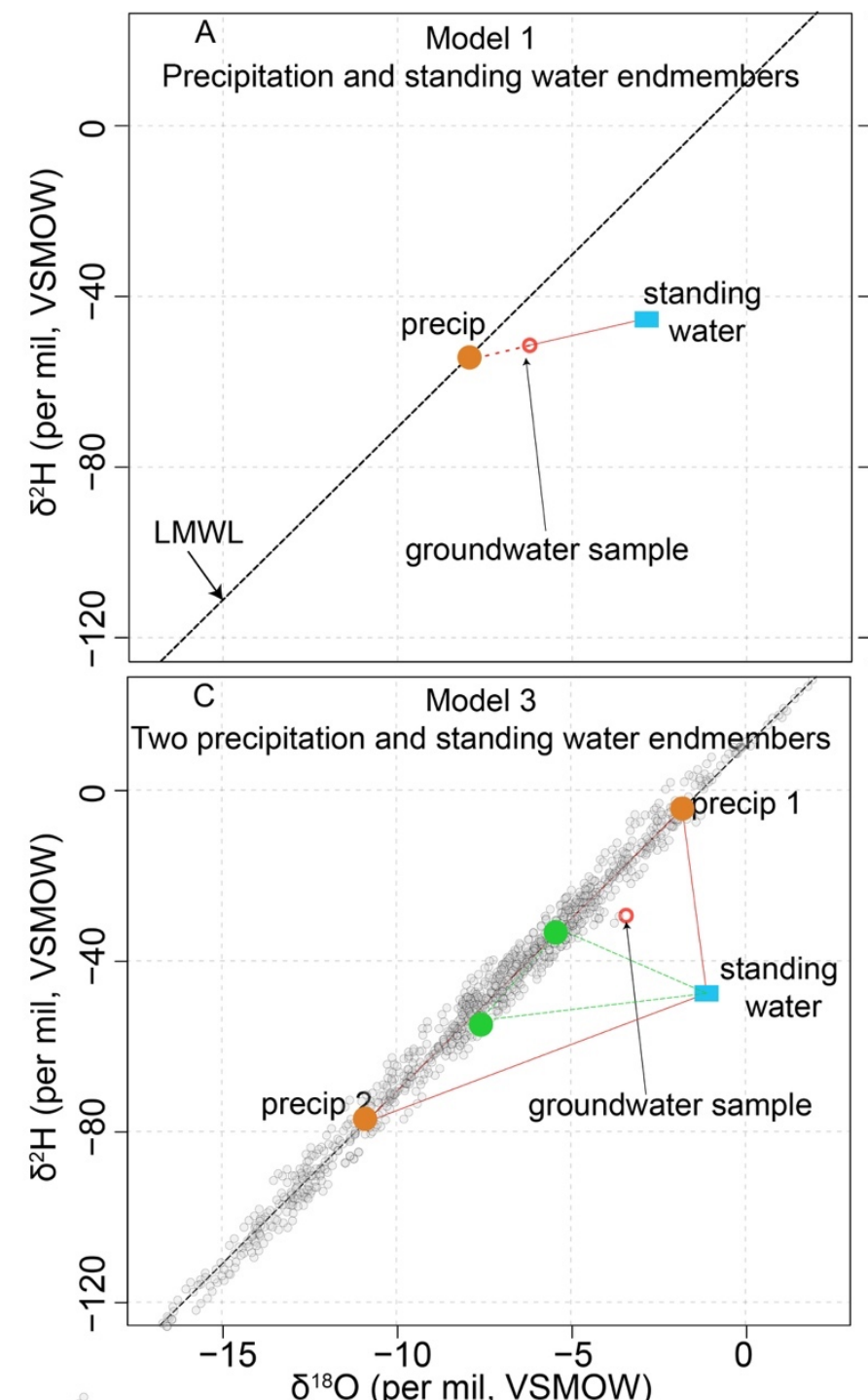

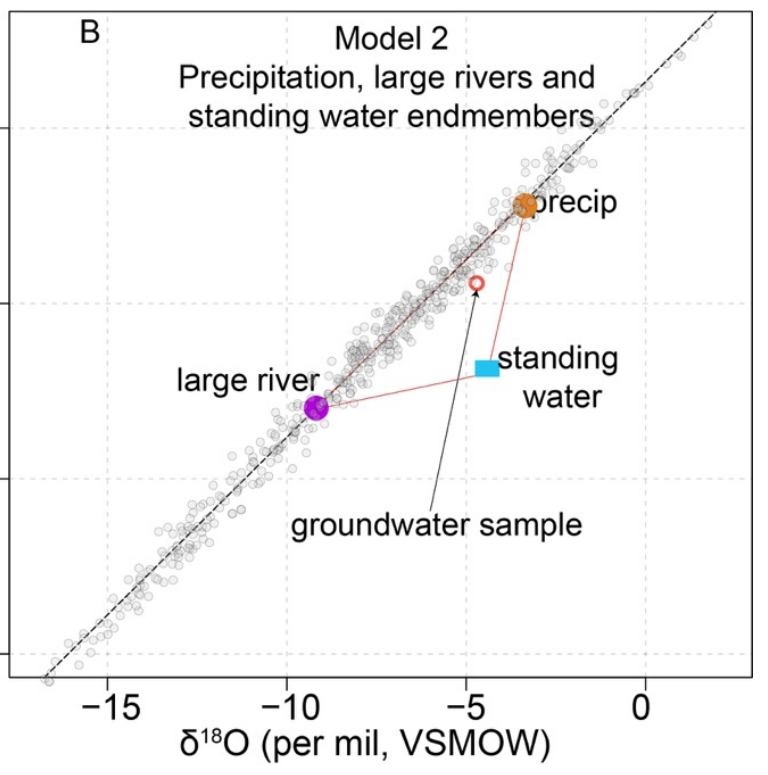

Solvable mixing triangle

(9)

Unsolvable mixing triangle

Figure 5: Graphical illustration of the three mixing models. In model 1 (A), groundwater is modeled as a mixture of precipitation and standing water. The line joining the surface water endmember and the groundwater (solid red) is extended to join the LMWL (dashed red). The point of intersection is the precipitation endmember isotope ratio. In model 2 (B), groundwater is modeled as a mixture of precipitation, large river and standing water endmembers. The small light gray circles are the 500 randomly generated precipitation isotope ratios. The red triangle connecting the large river (purple circle), standing water (blue rectangle) and precipitation (orange circle) endmembers illustrates one of the 500 possible triangles for each standing water sample. In the example shown here the groundwater sample (open red circle) falls within the red triangle and hence the mixing model is solvable. In model $3(\mathrm{C})$, groundwater is modeled as a mixture of 2 precipitation endmembers and a standing water endmember. For each standing water endmember, we generate two random distribution of 500 precipitation isotope values and from each of those distributions chose the precipitation endmember values (orange and green circles). The red triangle connecting two orange circles (precipitation endmembers) and blue rectangle (standing water endmember) results in a solvable mixing triangle i.e., groundwater isotope ratios can be modeled as a mixture of these three endmembers. The green triangle connecting two green circles 
985 (precipitation endmembers) and blue rectangle (standing water endmember) results in an 986 unsolvable mixing triangle i.e., linear mixing between these endmember values cannot explain the 987 observed groundwater isotope ratios. Figure S3 shows the isotopic range of the respective 988 endmembers. 

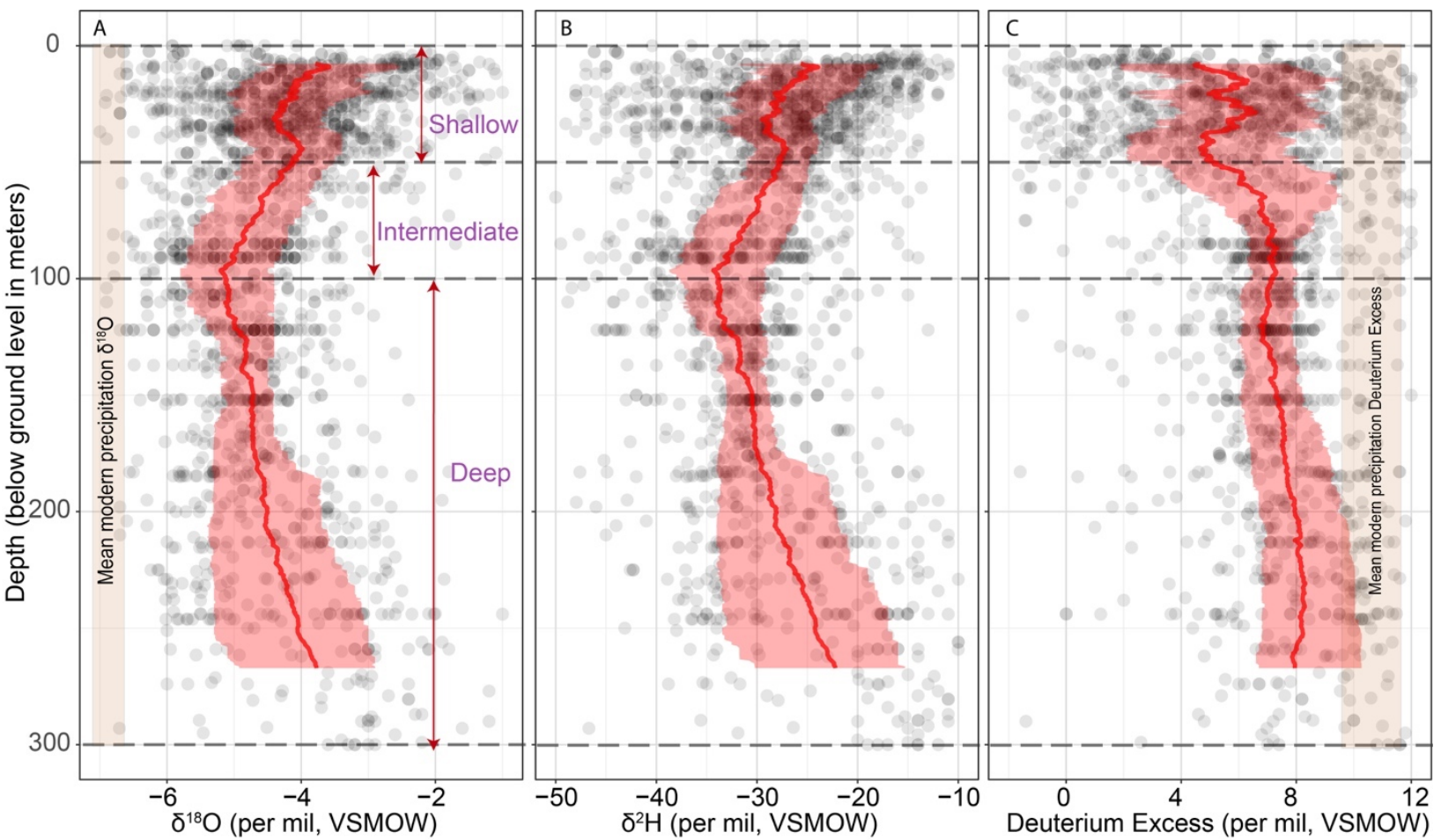

993

Figure 6: Depth plot versus groundwater $\delta^{18} \mathrm{O}(\mathrm{A}), \delta^{2} \mathrm{H}(\mathrm{B})$ and d-excess $(\mathrm{C})$. The red line and the light red shaded region are the moving depth average and the interquartile range of 200 groundwater samples starting from 0 meters depth. The black circles in panels (A-C) are the groundwater $\delta^{18} \mathrm{O}, \delta^{2} \mathrm{H}$ and deuterium-Excess values. The light brown rectangles in (A) and (C) are the mean modern precipitation $\delta^{18} \mathrm{O}$ and d-excess. 


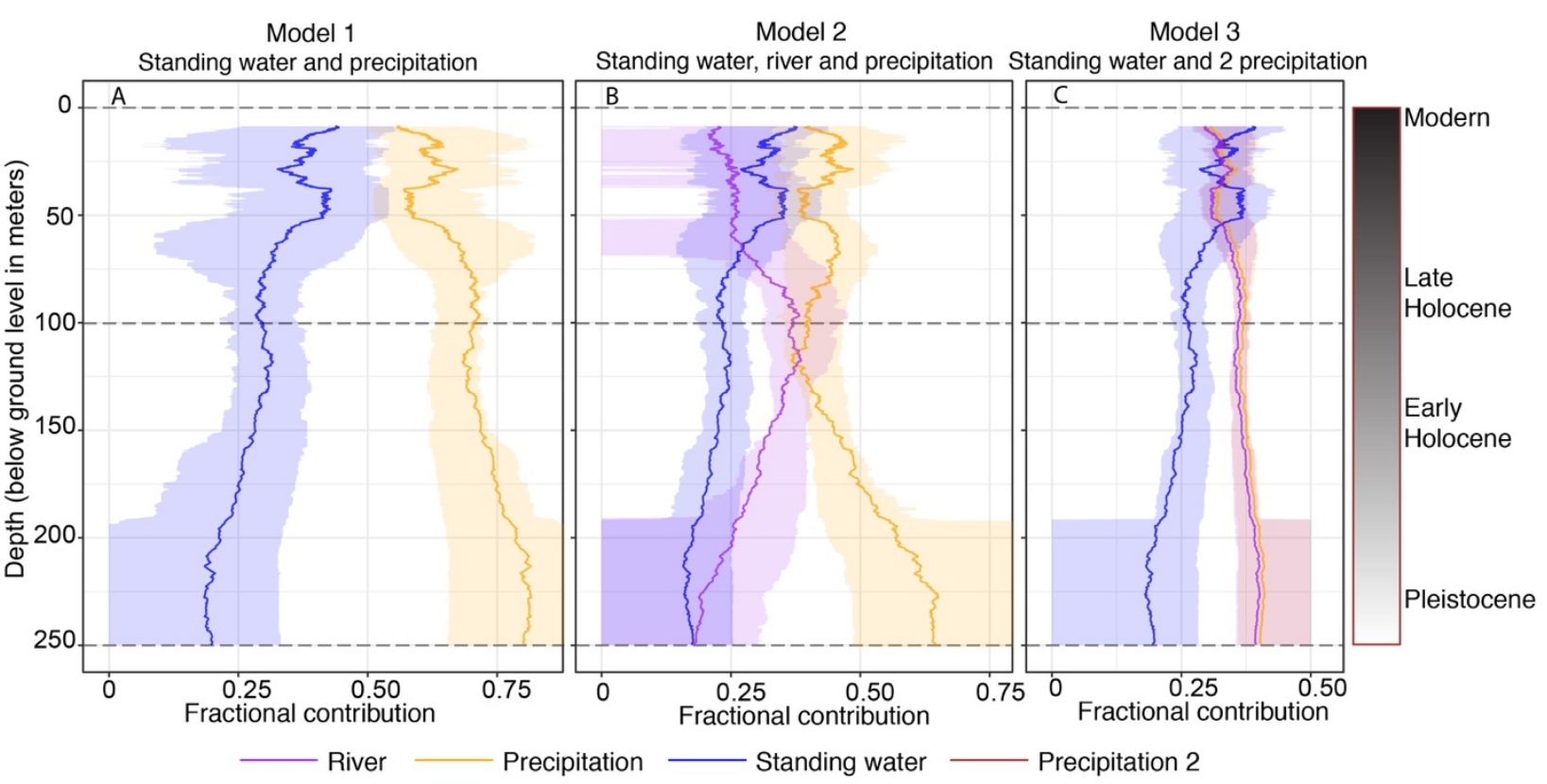

Figure 7: Proportional contribution of large rivers, surface water and precipitation sources versus depth. (A) Model 1, (B) model 2 and (C) model 3. The purple, blue and orange lines are the moving depth average of 200 groundwater samples. The purple, blue and orange shaded regions are the corresponding interquartile range. The dashed gray line at $100 \mathrm{~m}$ roughly differentiates between modern and late Holocene recharged water (0-100 m depth) with early Holocene and late Pleistocene water (100-250 m depth). See section "Limitations of using modern precipitation and river endmember values for deeper groundwater samples" in SM on the limitations of using modern endmember values for late Holocene - Early Pleistocene recharged deep waters 


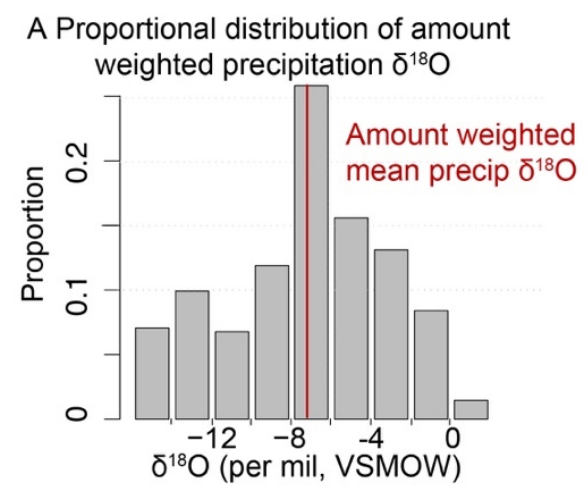

A1 Proportional distribution of precipitation $\delta^{18} \mathrm{O}$ estimated to be in groundwater - MODEL 1

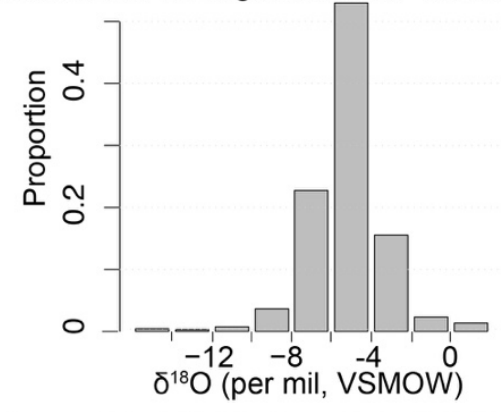

A2 Proportional distribution of precipitation $\delta^{18} \mathrm{O}$ estimated to be in groundwater - MODEL 2

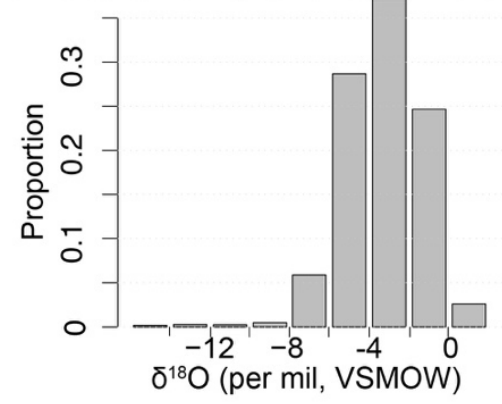

A3 Proportional distribution of precipitation $\delta^{18} \mathrm{O}$ estimated to be in groundwater - MODEL 3

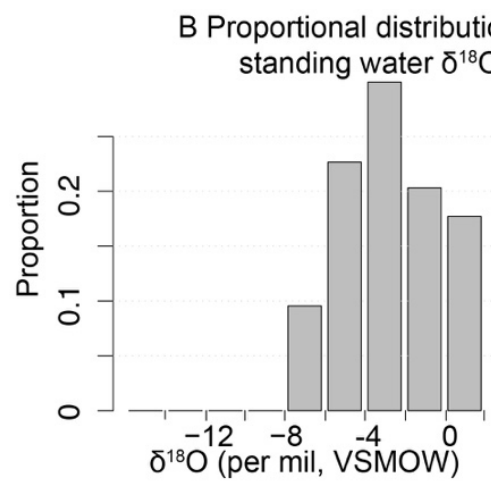

B1 Proportional distribution of standing water $\delta^{18} \mathrm{O}$ estimated to be in groundwater - MODEL 1

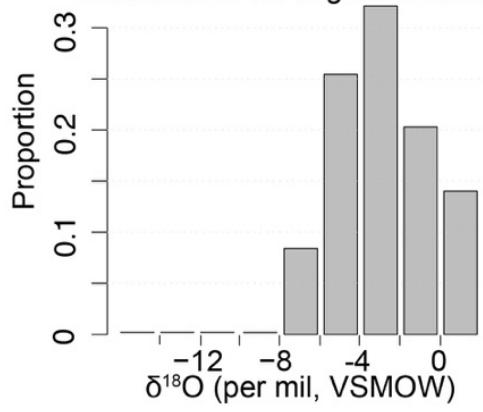

B2 Proportional distribution of standing water $\delta^{18} \mathrm{O}$ estimated to be in groundwater - MODEL 2

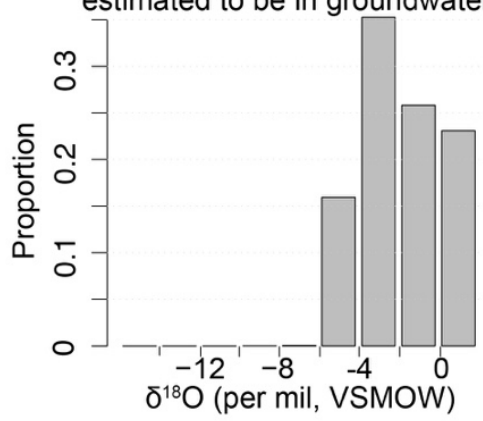

B3 Proportional distribution of standing water $\delta^{18} \mathrm{O}$ estimated to be in groundwater - MODEL 3

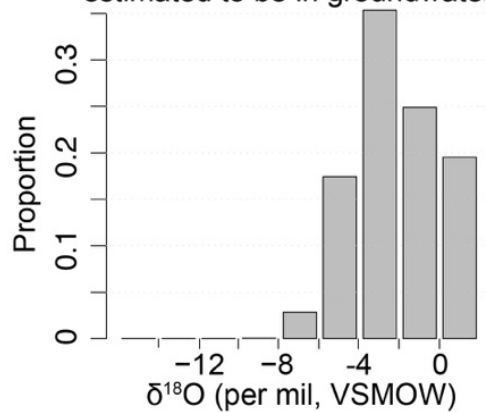

Figure 8: Distribution of input (A and $\mathrm{B}$ ) precipitation and standing water $\delta^{18} \mathrm{O}$ values. Distribution of modeled precipitation and standing water $\delta^{18} \mathrm{O}$ values in groundwater (A1 to B3). The red line in panels $\mathrm{A}$ is the amount weighted mean precipitation $\delta^{18} \mathrm{O}$ value. 


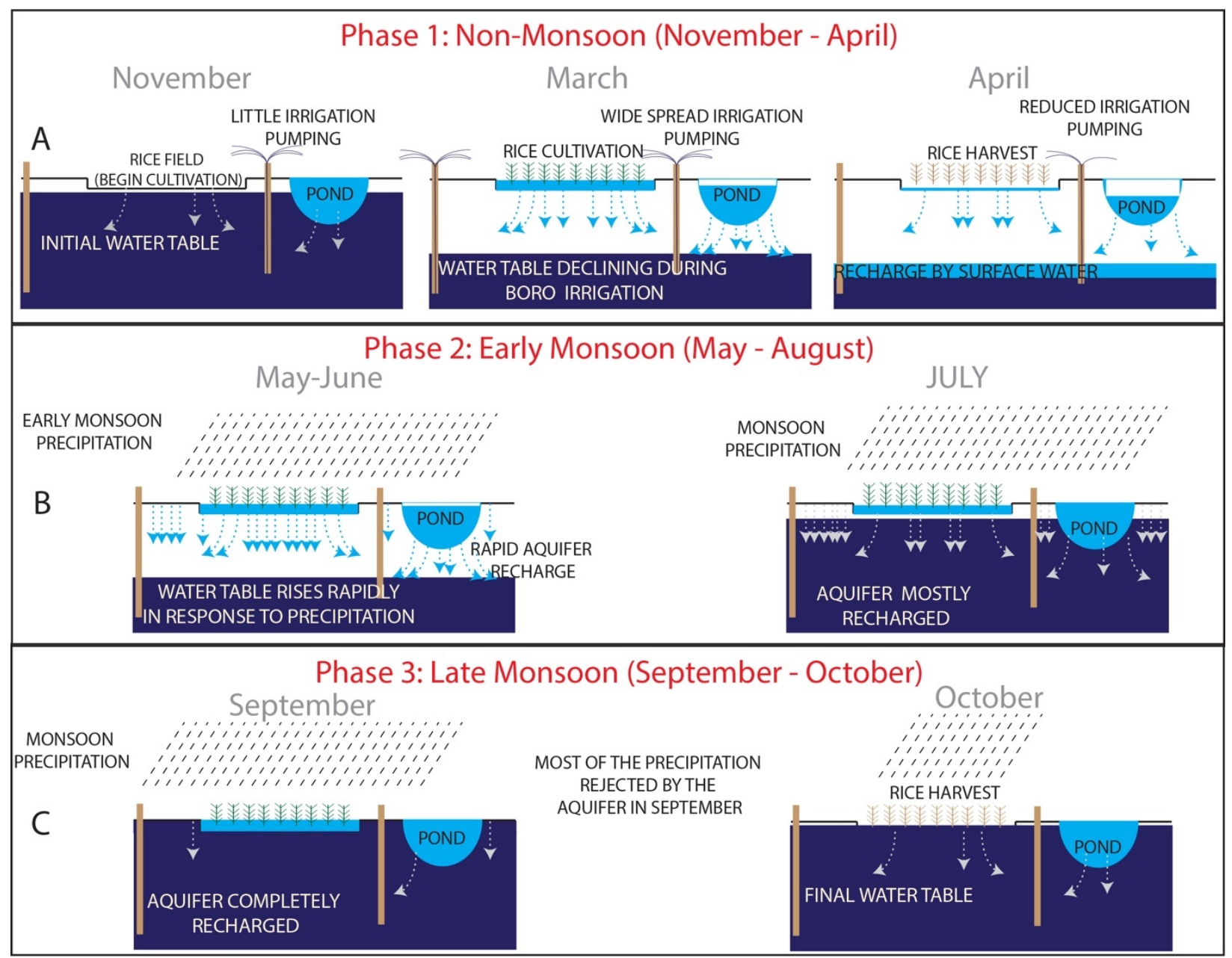

Figure 9: Conceptual recharge model for a shallow ( $<50 \mathrm{~m}$ deep) aquifer in the Bengal Basin from ponds and rice fields. For simplicity exchange between river and groundwater has been excluded from this figure. (A) In phase 1 (November - April), large amounts of groundwater are extracted for rice irrigation leading to a lowering of the water table. During the same period, the aquifers are also recharged due to lowering of the water table and higher head of ponds and rice fields. (B) In phase 2 (May - July), the shallow groundwater starts to recharge rapidly in response to the incoming monsoon precipitation and by July the aquifer is mostly 1018 recharged. (C) During the early part of phase 3 (September), the aquifers are completely 1019 replenished and most of the subsequent monsoon precipitation is rejected by the aquifer. By the end of phase 3 (October), monsoon has finished, and the flood waters have receded, beginning a paths. 


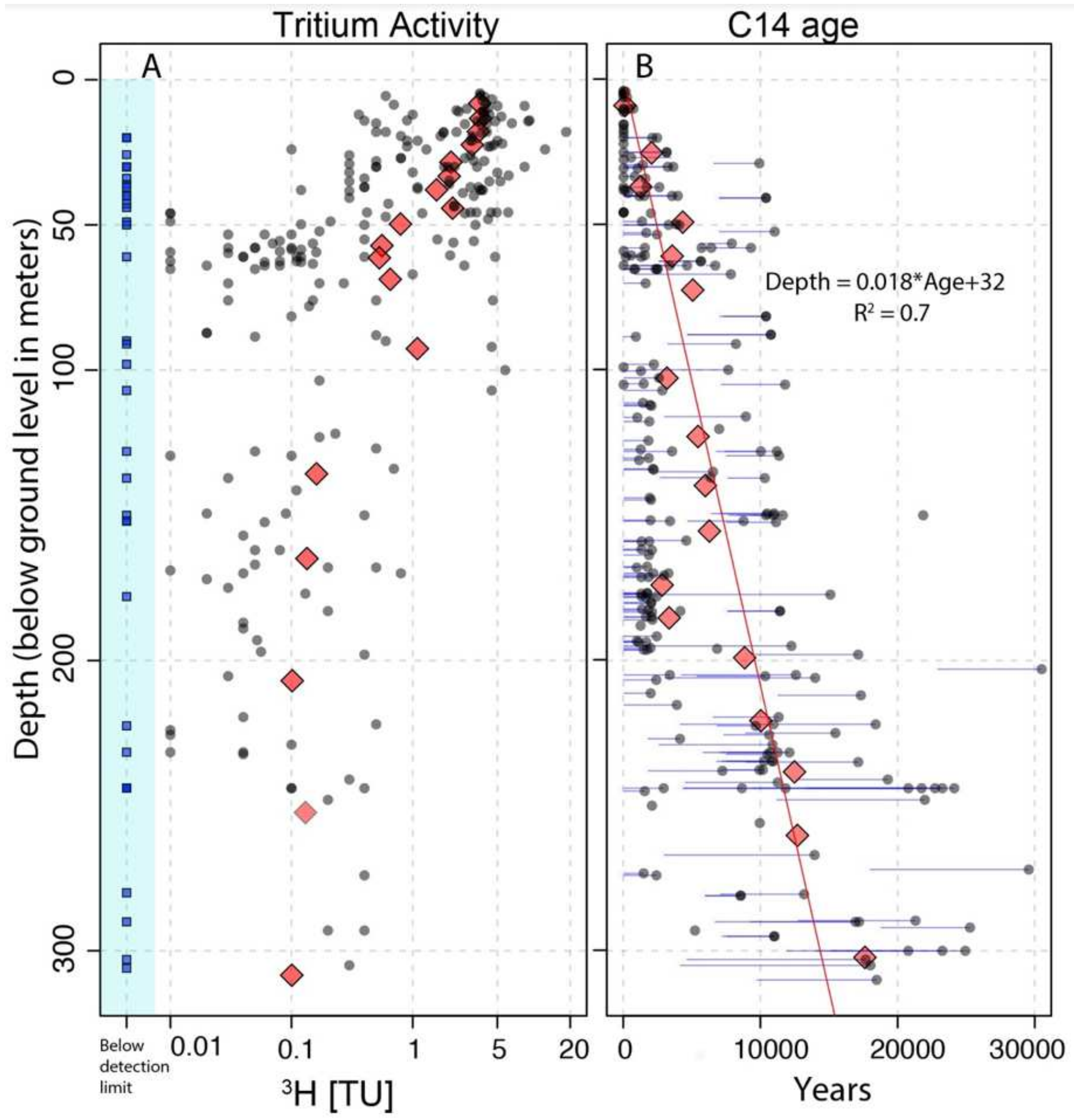

Figure 1

Tritium activity and $14 \mathrm{C}$ ages at different depths from across the Bengal Basin. Tritium activity $(A)$ and uncorrected groundwater $\mathrm{C} 14$ ages (B) shown in black circles. The red diamonds represent average over 15 measurements. Blue squares in panel $A$ are values below detection limit, which varies from study to 
study (Table S2). The horizontal lines in panel B represent corrected ages after accounting for radiocarbon-dead dissolved inorganic carbon using the method described in reference (104). Red line in panel B is the best fit line to the depth averaged C14 ages (red diamonds). See tables S2 and S3 for data source.
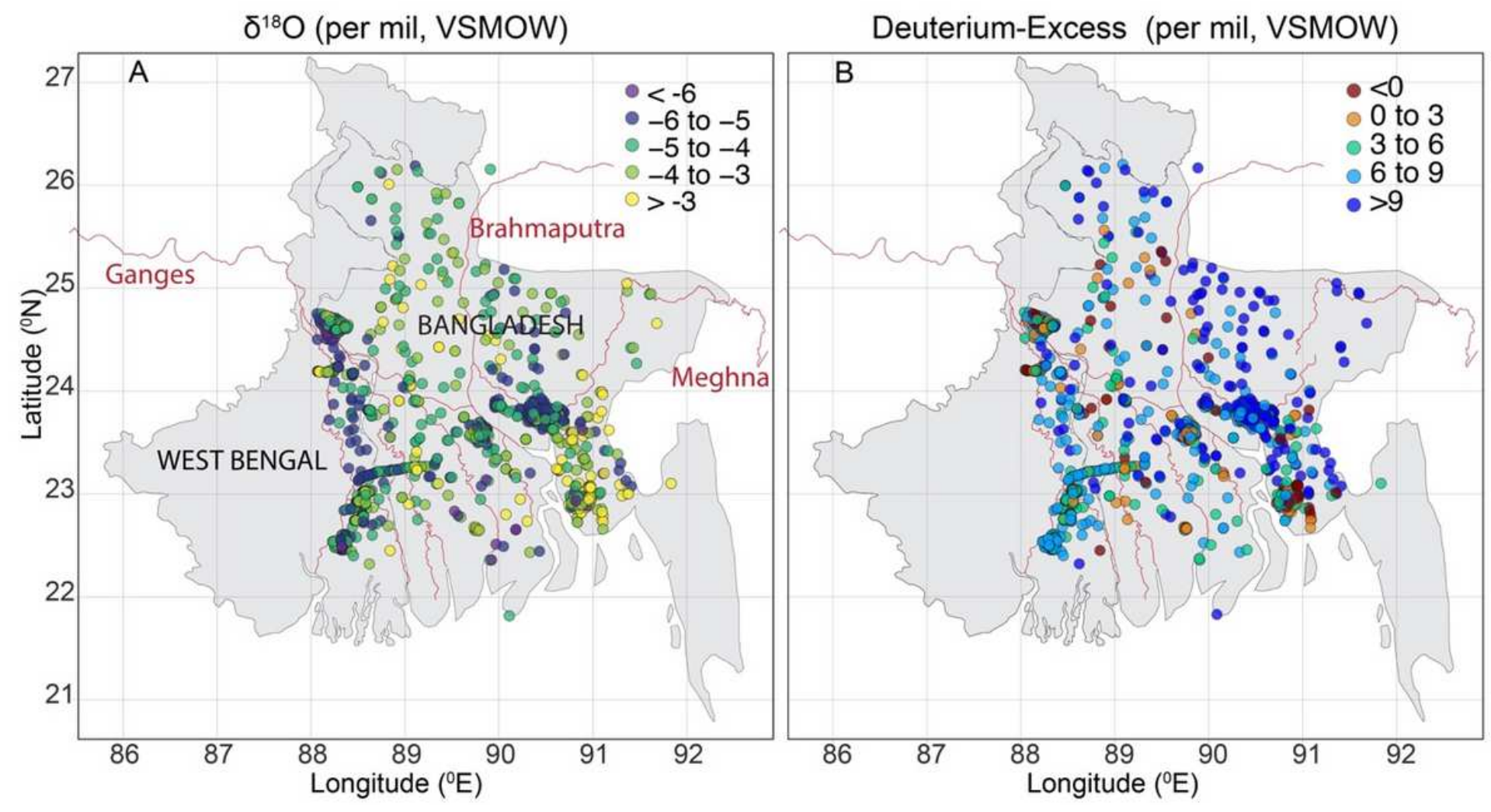

\section{Figure 2}

Spatial distribution of groundwater samples. $\delta 180(A)$ and d-excess (B) of georeferenced groundwater samples (circles) across the Bengal basin (Bangladesh and West Bengal, India). The three major rivers Ganges, Brahmaputra and Meghna and their tributaries are shown in red lines. Samples that were not georeferenced but included in the mixing model analysis have not been shown here. Groundwater $\delta 180$ and d-excess values across the basin were not spatially correlated (Moran's I statistics was 0.18 and 0.11 , $p<0.005$ for $\delta 180$ and d-excess respectively). Note: The designations employed and the presentation of the material on this map do not imply the expression of any opinion whatsoever on the part of Research Square concerning the legal status of any country, territory, city or area or of its authorities, or concerning the delimitation of its frontiers or boundaries. This map has been provided by the authors. 

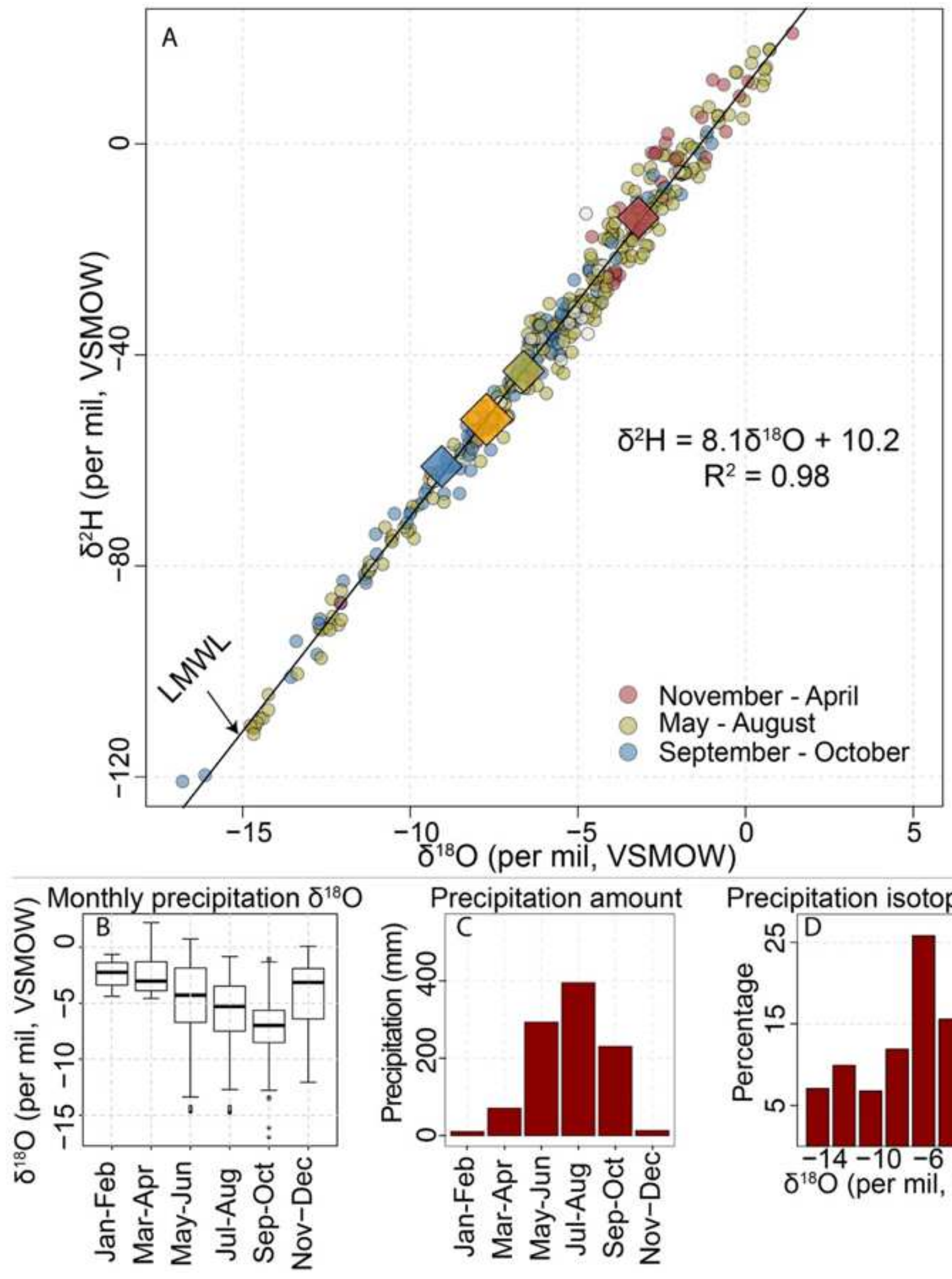

Precipitation isotopic proportion

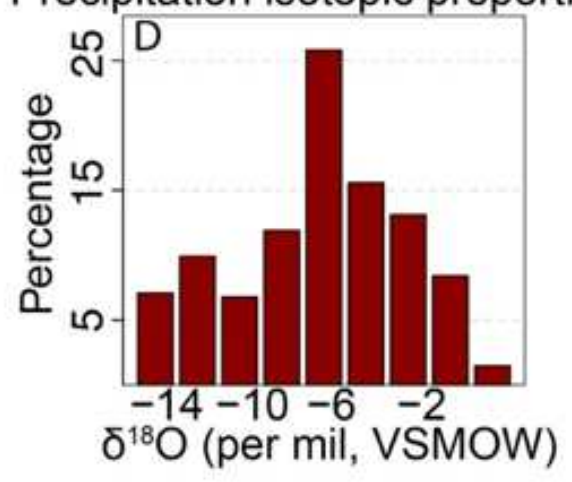

Figure 3

Precipitation isotope ratios in the Bengal Basin. (A) Precipitation stable isotope values from Bengal basin. Black line is the local meteoric water line ( $L M W L)$. Precipitation samples collected in dry months (November - May), early monsoon (June - July) and late monsoon (August - October) are colored red, green and blue respectively. The orange diamond is the amount-weighted mean precipitation isotope value for the Bengal Basin. The red, green and blue diamonds are the amount-weighted mean 
precipitation isotope values for dry season, early monsoon and late monsoon seasons. (B) Monthly precipitation $\delta 180$ values. (C) Average precipitation amount. (D) Proportion of rainfall amount grouped by their isotopic composition. Please refer to Figure S1 and S2 for spatial pattern in precipitation amount and precipitation $\delta 180$ values.

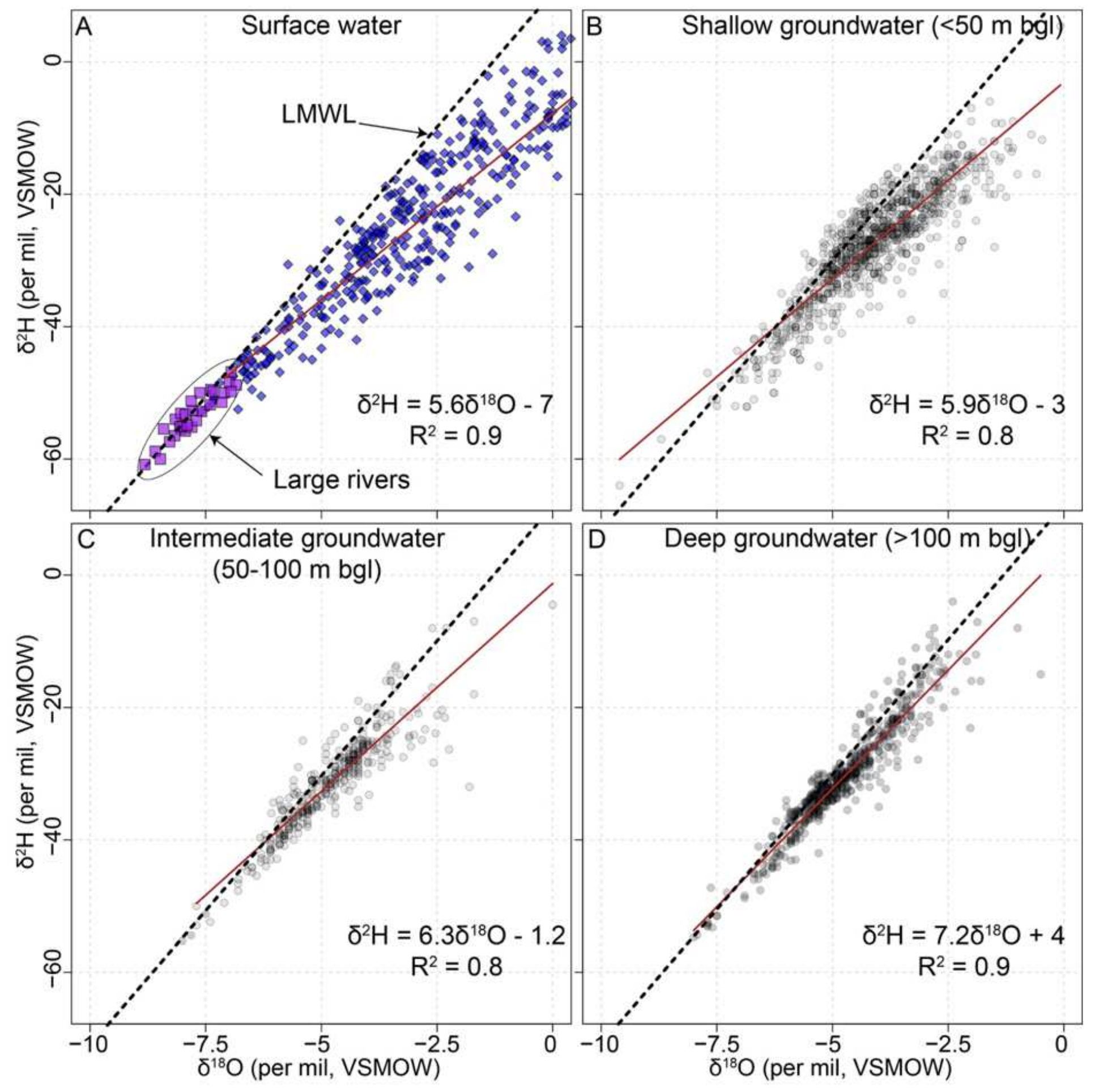

Figure 4

Surface and groundwater isotope ratios. Stable isotope values of surface water (A), shallow (B), intermediate (C) and deep (D) wells in the Bengal Basin The local evaporation line (LEL) for surface water 
$(A)$ is shown in brown line. Purple squares and blue diamonds in panel $(A)$ are the isotope ratios of large rivers and standing water respectively Dark red line in panels (A-D) are the respective groundwater lines for shallow, intermediate and deep wells. The equations are the best fit evaporation line (panel A) and groundwater lines (panels B-D). Black dashed line in each panel is the LMWL. For clarity, very enriched standing and groundwater samples $(\delta 180>0 \%)$ and depleted river samples $(\delta 180<-10 \%)$ have been removed from the figure.
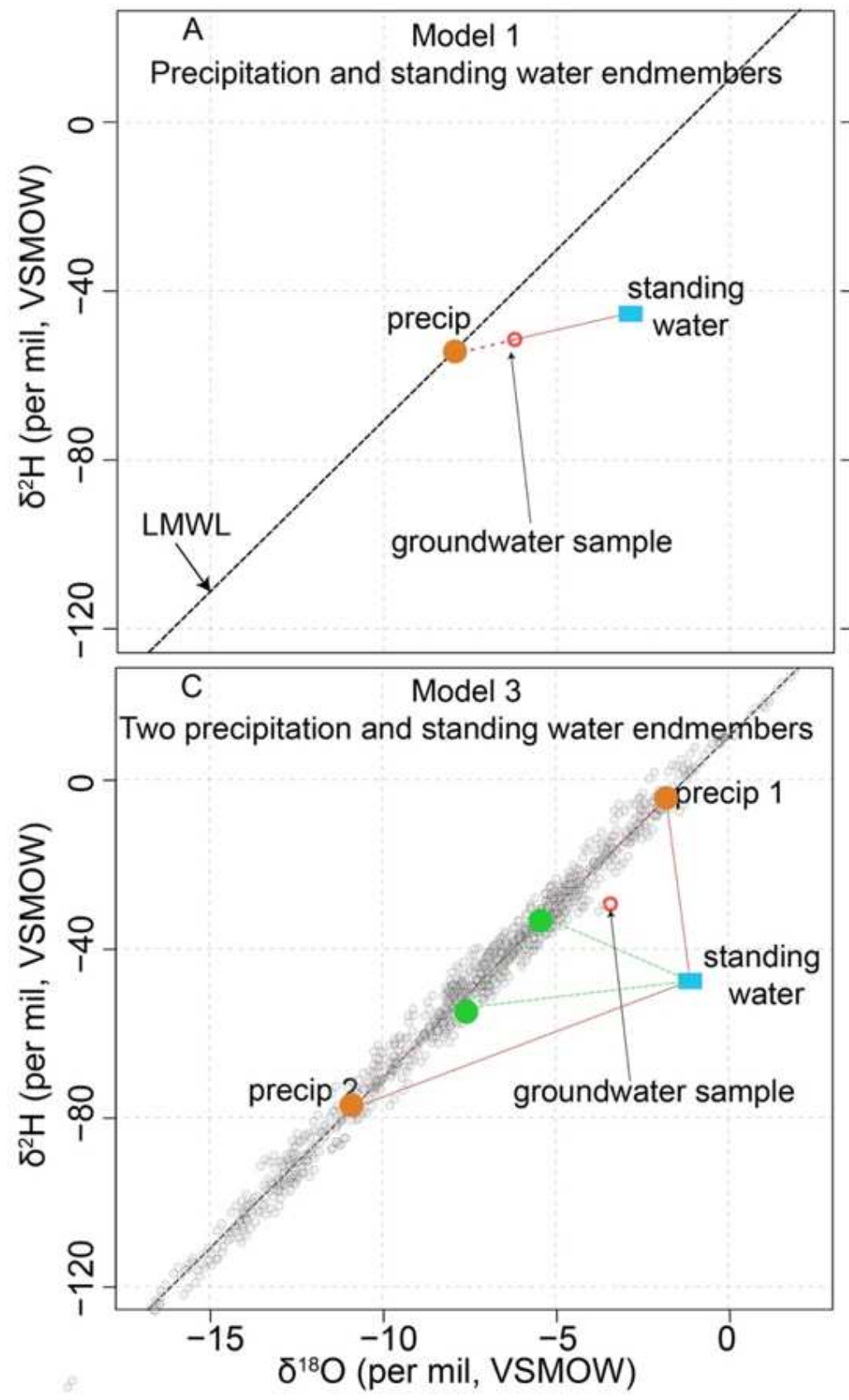
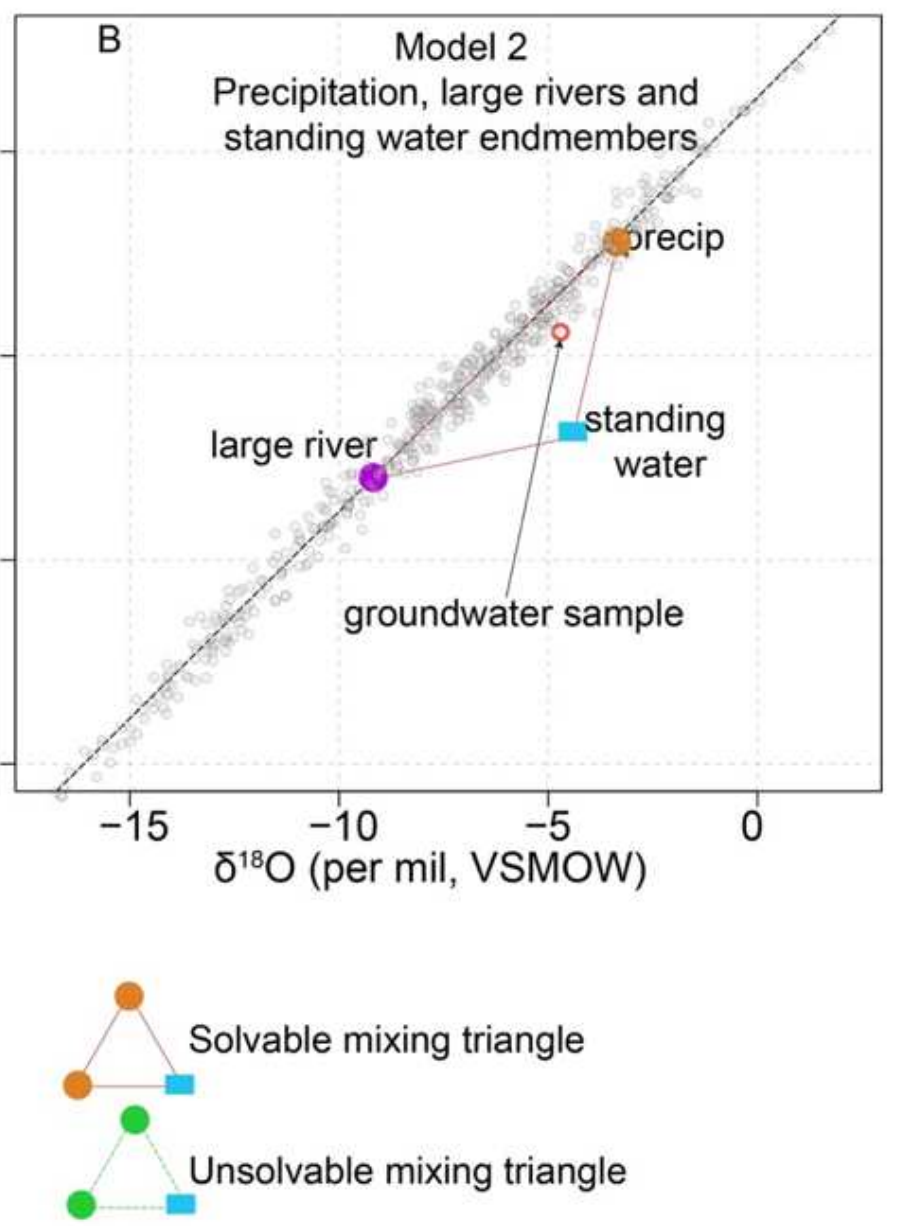

\section{Figure 5}

Graphical illustration of the three mixing models. In model $1(A)$, groundwater is modeled as a mixture of precipitation and standing water. The line joining the surface water endmember and the groundwater (solid red) is extended to join the LMWL (dashed red). The point of intersection is the precipitation 
endmember isotope ratio. In model 2 (B), groundwater is modeled as a mixture of precipitation, large river and standing water endmembers. The small light gray circles are the 500 randomly generated precipitation isotope ratios. The red triangle connecting the large river (purple circle), standing water (blue rectangle) and precipitation (orange circle) endmembers illustrates one of the 500 possible triangles for each standing water sample. In the example shown here the groundwater sample (open red circle) falls within the red triangle and hence the mixing model is solvable. In model 3 (C), groundwater is modeled as a mixture of 2 precipitation endmembers and a standing water endmember. For each standing water endmember, we generate two random distribution of 500 precipitation isotope values and from each of those distributions chose the precipitation endmember values (orange and green circles). The red triangle connecting two orange circles (precipitation endmembers) and blue rectangle (standing water endmember) results in a solvable mixing triangle i.e., groundwater isotope ratios can be modeled as a mixture of these three endmembers. The green triangle connecting two green circles (precipitation endmembers) and blue rectangle (standing water endmember) results in an unsolvable mixing triangle i.e., linear mixing between these endmember values cannot explain the observed groundwater isotope ratios. Figure S3 shows the isotopic range of the respective endmembers.

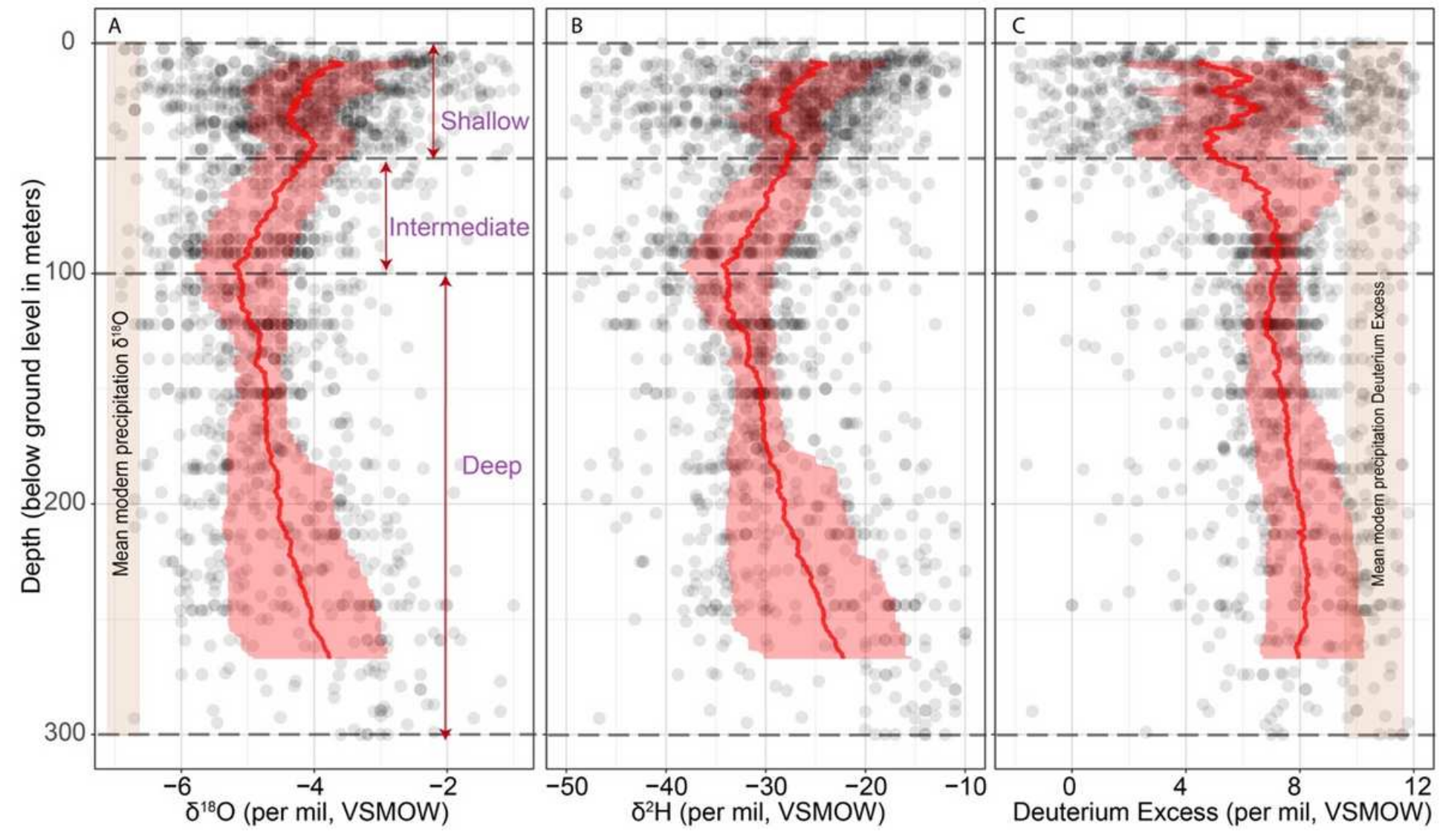

\section{Figure 6}

Depth plot versus groundwater $\delta 180(\mathrm{~A}), \delta 2 \mathrm{H}(\mathrm{B})$ and d-excess $(\mathrm{C})$. The red line and the light red shaded region are the moving depth average and the interquartile range of 200 groundwater samples starting from 0 meters depth. The black circles in panels $(A-C)$ are the groundwater $\delta 180, \delta 2 \mathrm{H}$ and deuterium- 
Excess values. The light brown rectangles in $(A)$ and $(C)$ are the mean modern precipitation $\delta 180$ and $d-$ excess.

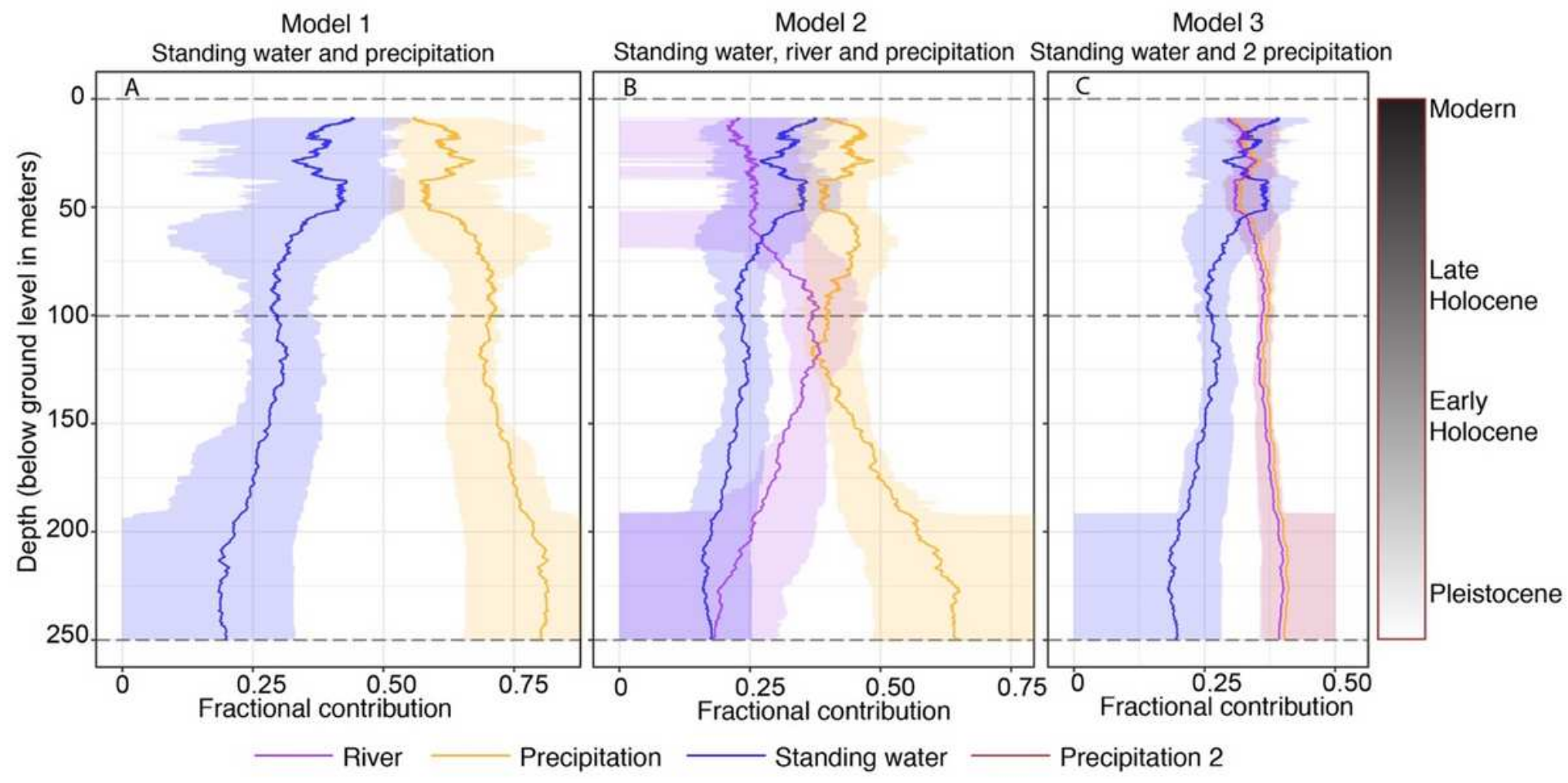

\section{Figure 7}

Proportional contribution of large rivers, surface water and precipitation sources versus depth. (A) Model 1, (B) model 2 and (C) model 3. The purple, blue and orange lines are the moving depth average of 200 groundwater samples. The purple, blue and orange shaded regions are the corresponding interquartile range. The dashed gray line at $100 \mathrm{~m}$ roughly differentiates between modern and late Holocene recharged water (0-100 $\mathrm{m}$ depth) with early Holocene and late Pleistocene water (100-250 m depth). See section "Limitations of using modern precipitation and river endmember values for deeper groundwater samples" in SM on the limitations of using modern endmember values for late Holocene - Early Pleistocene recharged deep waters 
A Proportional distribution of amount weighted precipitation $\delta^{18} \mathrm{O}$

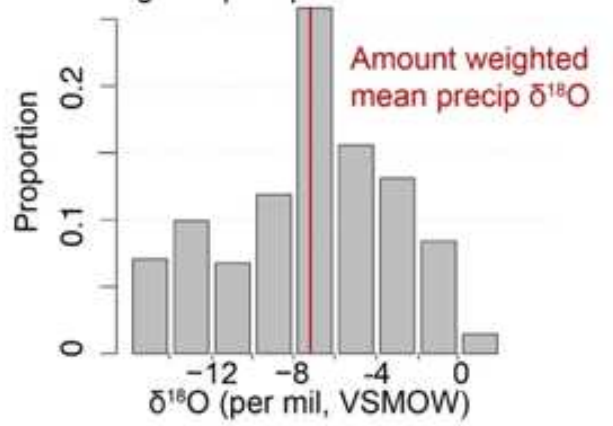

A1 Proportional distribution of precipitation $\delta^{18} \mathrm{O}$ estimated to be in groundwater-MODEL 1

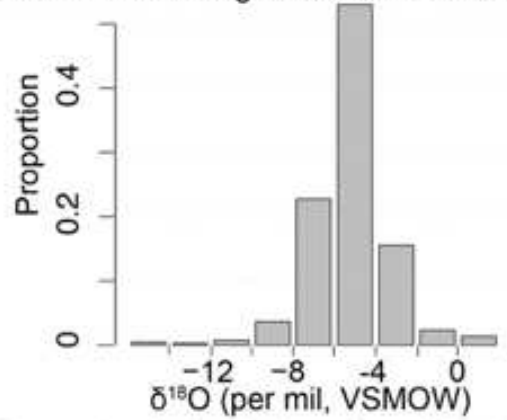

A2 Proportional distribution of precipitation $\delta^{18} \mathrm{O}$ estimated to be in groundwater-MODEL 2

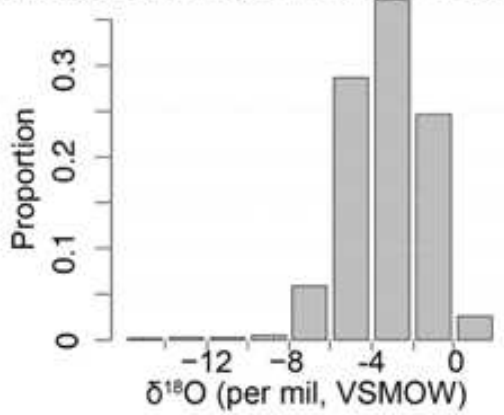

A3 Proportional distribution of precipitation $\delta^{18} \mathrm{O}$ estimated to be in groundwater - MODEL 3

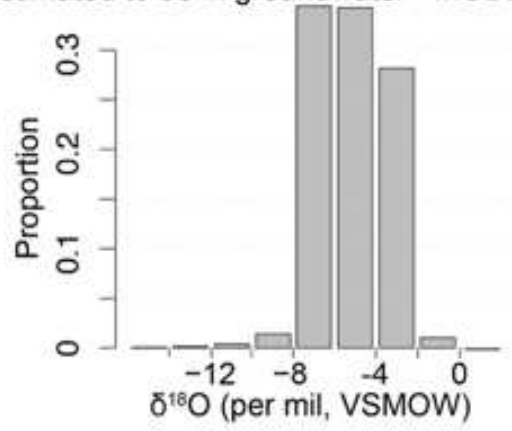

B Proportional distribution of standing water ${ }^{18} \mathrm{O}$

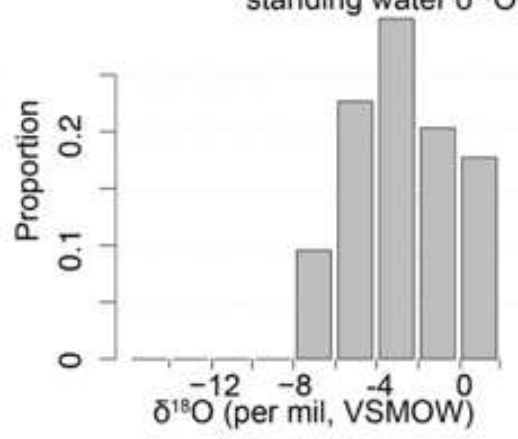

B1 Proportional distribution of standing water $\delta^{18} \mathrm{O}$ estimated to be in groundwater-MODEL 1

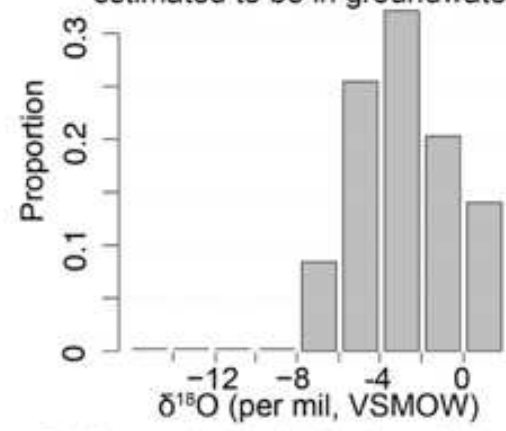

B2 Proportional distribution of standing water $\delta^{18} \mathrm{O}$

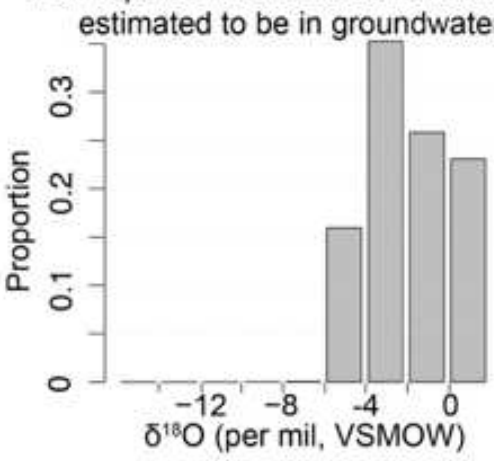

B3 Proportional distribution of standing water $\delta^{18} \mathrm{O}$ estimated to be in groundwater - MODEL 3

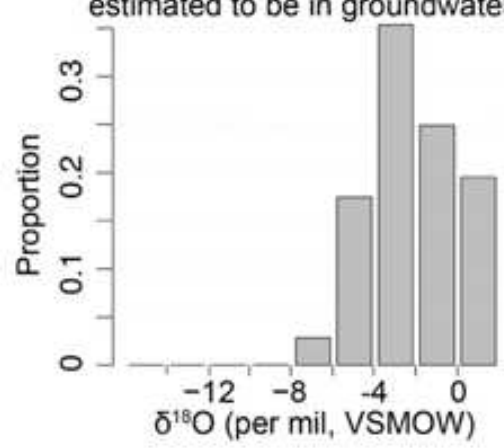

\section{Figure 8}

Distribution of input ( $A$ and $B$ ) precipitation and standing water $\delta 180$ values. Distribution of modeled precipitation and standing water $\delta 180$ values in groundwater (A1 to B3). The red line in panels $A$ is the amount weighted mean precipitation $\delta 180$ value. 


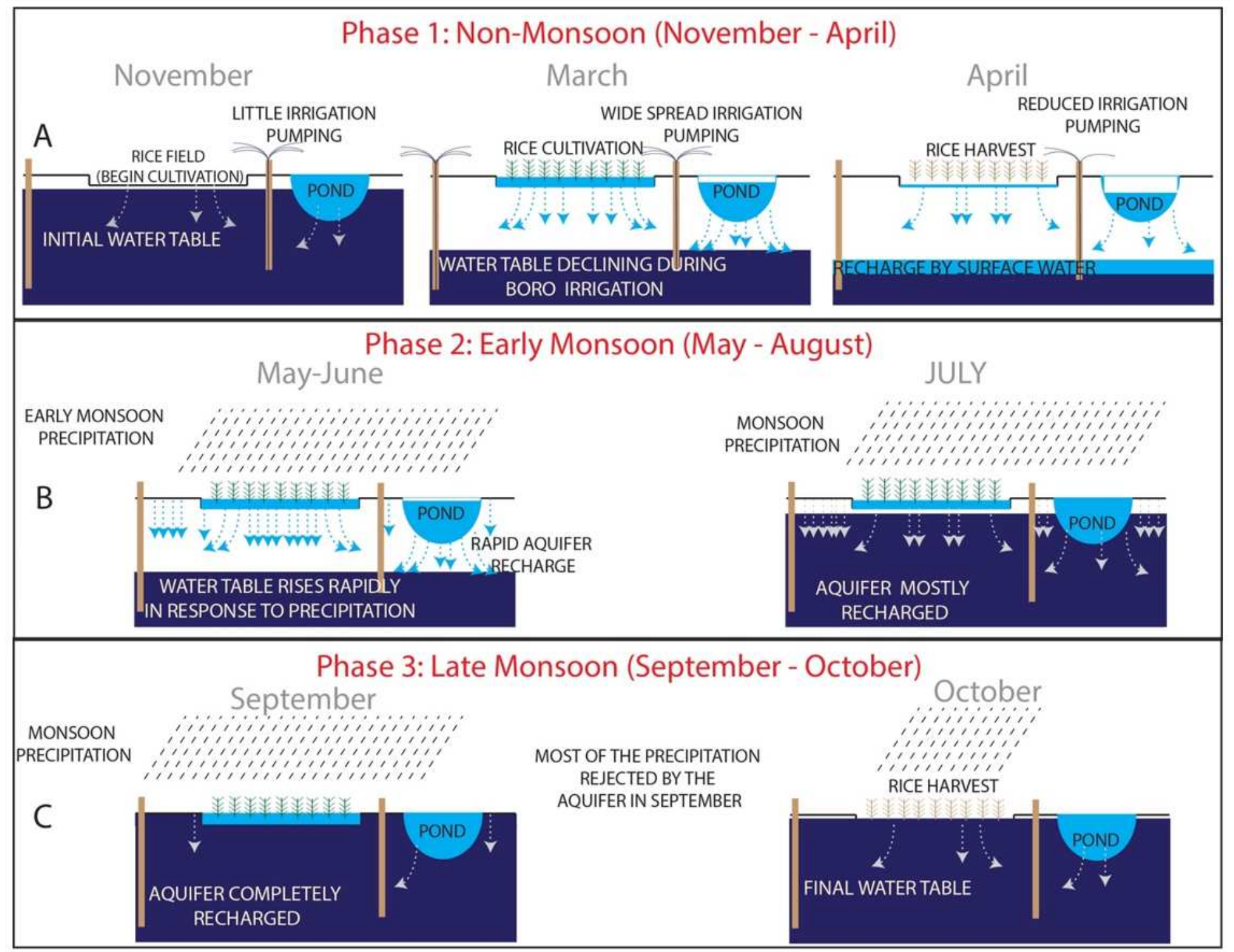

Figure 9

Conceptual recharge model for a shallow ( $<50 \mathrm{~m}$ deep) aquifer in the Bengal Basin from ponds and rice fields. For simplicity exchange between river and groundwater has been excluded from this figure. (A) In phase 1 (November - April), large amounts of groundwater are extracted for rice irrigation leading to a lowering of the water table. During the same period, the aquifers are also recharged due to lowering of the water table and higher head of ponds and rice fields. (B) In phase 2 (May - July), the shallow groundwater starts to recharge rapidly in response to the incoming monsoon precipitation and by July the aquifer is mostly recharged. (C) During the early part of phase 3 (September), the aquifers are completely replenished and most of the subsequent monsoon precipitation is rejected by the aquifer. By the end of phase 3 (October), monsoon has finished, and the flood waters have receded, beginning a period of groundwater abstraction for irrigation. The blue and gray arrows illustrate the recharge paths.

\section{Supplementary Files}


This is a list of supplementary files associated with this preprint. Click to download.

- SupplementaryMaterialNCEE.docx 